Article

\title{
Inhibition of the Maillard Reaction by Phytochemicals Composing an Aqueous Coffee Silverskin Extract via a Mixed Mechanism of Action
}

\author{
Miguel Rebollo-Hernanz ${ }^{1,2}{ }^{\circledR}$, Beatriz Fernández-Gómez ${ }^{1}$, Miguel Herrero ${ }^{1}$ (D), \\ Yolanda Aguilera ${ }^{1,2}$, María A. Martín-Cabrejas ${ }^{1,2}$, Jaime Uribarri ${ }^{3}$ \\ and María Dolores del Castillo ${ }^{1, *(1)}$ \\ 1 Institute of Food Science Research (CIAL, UAM-CSIC), C/Nicolás Cabrera, 9, Universidad Autónoma de \\ Madrid, 28049 Madrid, Spain; miguel.rebollo@uam.es (M.R.-H.); b.fernandez@csic.es (B.F.-G.); \\ m.herrero@csic.es (M.H.); yolanda.aguilera@uam.es (Y.A.); maría.martin@uam.es (M.A.M.-C.) \\ 2 Department of Agricultural Chemistry and Food Science, Faculty of Science, C/Francisco Tomás y Valiente, 7, \\ Universidad Autónoma de Madrid, 28049 Madrid, Spain \\ 3 Department of Medicine, The Icahn School of Medicine at Mount Sinai, 1468 Madison Ave, New York, \\ NY 10029, USA; jaime.uribarri@mountsinai.org \\ * Correspondence: mdolores.delcastillo@csic.es; Tel.: +34-910017900 (ext. 953)
}

Received: 3 September 2019; Accepted: 21 September 2019; Published: 25 September 2019

\begin{abstract}
This work aimed to evaluate the contribution of isoflavones and melatonin to the aqueous extract obtained from the coffee silverskin (CSE) antiglycative properties, which has not been previously studied. To achieve this goal, two model systems constituted by bovine serum albumin (BSA) and reactive carbonyls (glucose or methylglyoxal) in the presence or absence of pure phytochemicals (chlorogenic acid (CGA), genistein, and melatonin) and CSE were employed. Glucose was used to evaluate the effect on the formation of glycation products formed mainly in the early stage of the reaction, while methylglyoxal was employed for looking at the formation of advanced products of the reaction, also called methylglyoxal-derivative advanced glycation end products (AGE) or glycoxidation products. CGA inhibited the formation of fructosamine, while genistein and melatonin inhibited the formation of advanced glycation end products and protein glycoxidation. It was also observed that phenolic compounds from CSE inhibited protein glycation and glycoxidation by forming BSA-phytochemical complexes. CSE showed a significant antiglycative effect $(p<0.05)$. Variations in the UV-Vis spectrum and the antioxidant capacity of protein fractions suggested the formation of protein-phytochemical complexes. Fluorescence quenching and in silico analysis supported the formation of antioxidant-protein complexes. For the first time, we illustrate that isoflavones and melatonin may contribute to the antiglycative/antiglycoxidative properties associated with CSE. CGA, isoflavones, and melatonin composing CSE seem to act simultaneously by different mechanisms of action.
\end{abstract}

Keywords: advanced glycation end products (AGE); antioxidants; chlorogenic acid; coffee silverskin extract; genistein; melatonin; protein glycation; protein glycoxidation; Maillard reaction

\section{Introduction}

The Maillard reaction results from the reaction between a reactive carbonyl group of reducing sugars and the free amino groups of proteins, without the participation of enzymes, giving rise to Amadori products. $\alpha$-Dicarbonyls, such as glyoxal (GO), methylglyoxal (MGO), and deoxyosones, are reactive intermediate species able to accelerate the protein glycation reaction due to their higher 
reactivity compared to glucose. Oxidative (glycoxidation) and non-oxidative subsequent reactions result in the formation of a variety of advanced glycation end products (AGE) [1].

AGEs are formed continuously in the human body at a slow rate, but this rate is increased by hyperglycaemia and oxidative stress status [2]. Moreover, research has shown that dietary AGEs, indistinguishable from endogenous AGEs, are important contributors to the body AGE pool [3]. Dietary AGEs are at least partially absorbed from the gut and interact systemically with the AGE receptor (RAGE) [4]. AGEs might also form in the gut during food digestion [5]. AGEs have been associated with oxidative stress and inflammation, underlying abnormalities behind most non-infectious chronic diseases, including cardiovascular disease, diabetes, chronic kidney disease, and neurodegenerative diseases [6].

The inhibition of the Maillard reaction in vivo has been obtained through different strategies over the years [7]. Finding inhibitors of the Maillard reaction in foods and in vivo is still an ongoing quest. Counteracting the Maillard reaction by the addition of natural extracts and phytochemicals has also been targeted, as well as the removal or modification of one of the reactants (the amino groups or the reducing sugars) and the trapping of $\alpha$-dicarbonyl compounds. Some phenolic compounds have also been proposed to react with amines to form either benzoquinone imines or amine-quinone adducts via a Michael addition, thus avoiding the progress of the reaction [8,9]. Overall, antiglycative mechanisms comprise any mechanisms that delay the Maillard and subsequent glycoxidation reactions [10], also including the scavenging of hydroxyl and superoxide radicals, the reduction of the generation of reactive carbonyl or dicarbonyl groups, and the chelation of metal ions promoting oxidative reactions.

Hence, the search for a natural product with inhibitory potential against the Maillard reaction is a challenging strategy to evaluate food products containing phytochemicals of interest. Coffee by-products have been proposed as food ingredients loaded with bioactive compounds that are safe to use [11,12]. Coffee silverskin, the outer layer of green coffee beans and a by-product of the roasting procedure, is a good source of phenolic compounds, such as chlorogenic acid (CGA) [13]. The inhibitory effect of CGA and coffee silverskin is associated with its carbonyl trapping capacity as well as its ability to react with side-chains of protein amino residues blocking the reaction sites [14]. Nevertheless, the overall antiglycative capacity of coffee silverskin could also be associated with phytochemicals other than CGA, such as isoflavones and alkaloids, and the mechanism of action of these other compounds from coffee silverskin is still not clearly understood. Genistein has been shown to inhibit the formation of AGE by forming adducts with MGO both in vitro and in vivo [15,16]. Other isoflavones also inhibit glycation [17]. Likewise, melatonin could present antiglycative properties [18]. However, no studies have described the presence of these compounds in coffee silverskin extracts nor their contribution to the antiglycative effect attributed to them.

We hypothesised that different phytochemical compounds from coffee silverskin, besides CGA, could provide antiglycative effects through different mechanisms. Hence, the present study aimed to identify other potential contributors to the antiglycative properties of coffee silverskin extract, besides CGA, by analysing the effects of a coffee silverskin aqueous extract and other pure compounds present therein, to assess their inhibitory effects against the Maillard reaction and their mechanisms in vitro and in silico.

\section{Materials and Methods}

\subsection{Materials}

All reagents and solvents used were of analytical grade. Bovine serum albumin (BSA), glucose, aminoguanidine, CGA, genistein, melatonin, caffeine, rutin, sodium azide, $O$-phthaldehyde (OPA), $N_{\alpha}$-acetyl-L-lysine, 1-deoxy-1-morfolinofructose (DMF), nitroblue tetrazolium (NBT), $o$-phenylenediamine (OPD), trichloroacetic acid (TCA), 2,4-dinitrophenylhydrazine (DNPH), guanidine, and the Folin-Ciocalteu reagent were supplied by Sigma-Aldrich (St. Louis, MO USA). Other chemicals and their suppliers were as follows: $\beta$-mercaptoethanol (Merck, Hohenbrunn, Germany), 
MGO and diammonium salt-2,2'-azino bis (3-ethylbenzthiazoline-6-sulfonic acid) (ABTS) from Fluka, (Buchs, Switzerland), and Bradford reagent from Bio-Rad (München, Germany). The Amicon ${ }^{\circledR}$ Ultra $0.5 \mathrm{~mL}$ centrifugal filter unit fitted with an Ultracel ${ }^{\circledR} 30 \mathrm{~K}$ regenerated cellulose membrane $(30 \mathrm{kDa}$ cut-off) was from Merck Millipore Ltd. (Cork, Ireland). Microtest 96-well polystyrene plates made from high-quality polystyrene were purchased from Sarstedt AG \& Co. (Nümbrecht, Germany). The AGE determination kit was supplied by Lamider ${ }^{\circledR}$ (Mexico D.F., Mexico). The Milli-Q water used was obtained using a purification system (Millipore, Molsheim, France).

\subsection{Coffee Silverskin Extract (CSE) Preparation}

Coffee silverskin from Arabica (Coffea arabica) and Robusta (Coffea canephora) species was provided by Qualery Culture S.L. (Val de Santo Domingo, Spain). CSE was prepared by aqueous extraction according to a patented procedure [19]. Briefly, $50 \mathrm{~mL}$ of boiling water was added to $2.5 \mathrm{~g}$ of coffee silverskin (Arabica: Robusta, 1:1, w/w) and the mixture was maintained in continuous stirring for $10 \mathrm{~min}$. The mixture was filtered through Whatman qualitative filter paper (Whatman, Mainstone, UK), grade 4, and was freeze-dried. The powdered extracts were stored in dark and dry conditions until further analysis.

\subsection{Phytochemical Characterisation of CSE}

\subsubsection{Total Phenolic Compounds (TPC)}

TPCs were determined by the Folin-Ciocalteu colourimetric method [20]. The reduction reaction was carried out in $210 \mu \mathrm{L}$ total volume in 96-well microplates. Ten $\mu \mathrm{L}$ of the sample was added to $150 \mu \mathrm{L}$ of Folin-Ciocalteu reagent (diluted 1:14, $v / v$ in Milli-Q water). After exactly $3 \mathrm{~min}, 50 \mu \mathrm{L}$ of $\mathrm{Na}_{2} \mathrm{CO}_{3}(20 \%, w / v)$ was added into each well. Absorbance was recorded at $750 \mathrm{~nm}$ using a microplate reader BioTek PowerWave ${ }^{\mathrm{TM}}$ XS (BioTek Instruments, Winooski, VT, USA). Calibration curves were constructed using standard solutions of CGA $\left(0.1-1 \mathrm{mg} \mathrm{L}^{-1}\right)$, and results were expressed as $\mu \mathrm{g}$ CGA equivalents $\mathrm{mg}^{-1}$ ( $\mu \mathrm{g}$ CGAE $\left.\mathrm{mg}^{-1}\right)$.

\subsubsection{Total Flavonoids Content (TFC)}

TFC was quantified as previously described [21]. Briefly, $100 \mu \mathrm{L}$ of CSE was mixed with $30 \mu \mathrm{L}$ of $5 \% \mathrm{NaNO}_{2}$ and samples were incubated at room temperature for $5 \mathrm{~min}$. Subsequently, $30 \mu \mathrm{L}$ of $10 \%$ $\mathrm{AlCl}_{3}$ was added and incubated for $6 \mathrm{~min}$. Then, $100 \mu \mathrm{L}$ of $\mathrm{NaOH} 2 \mathrm{~mol} \mathrm{~L}^{-1}$ was added, vortexed, and the absorbance was read at $510 \mathrm{~nm}$. TFC was calculated with a calibration curve of rutin, and the results were expressed as $\mu \mathrm{g}$ rutin equivalents $\mathrm{mg}^{-1}\left(\mu \mathrm{g} \mathrm{RE} \mathrm{mg}^{-1}\right)$.

\subsubsection{Melatonin Quantification by High-Performance Liquid Chromatography-Electrospray} Ionization Tandem Mass Spectrometry (HPLC-ESI-MS/MS)

CSE was dissolved in Milli-Q water $\left(10 \mathrm{mg} \mathrm{mL}^{-1}\right)$ and passed through a $0.45 \mu \mathrm{m}$ pore-size nylon membrane syringe filter (Análisis Vínicos, Ciudad Real, Spain). Melatonin isolation and quantification were performed according to published instructions [22]. Melatonin was determined by HPLC-ESI-MS/MS triple quadrupole (Varian 1200 L with Atmospheric Pressure Ionization-Electrospray Ionisation (API-ES) between 10 and 1500 Da range mass). An Intensity Trio C18 (150 mm $\times 2.0 \mathrm{~mm}$ ID, S-3 $\mu \mathrm{m}, 12 \mathrm{~nm}$ BRYTC18032150) (Bruker, Billerica, MA, USA) column and a flow rate of $0.2 \mathrm{~mL}$ $\min ^{-1}$ were used. Acetonitrile containing $0.1 \%$ formic acid (solvent $\mathrm{A}$ ) and $0.1 \%$ formic acid in $\mathrm{H}_{2} \mathrm{O}$ (solvent $\mathrm{B}$ ) as mobile phase were pumped with the following gradient: $5 \%$ solvent $\mathrm{A}(0-4 \mathrm{~min}), 5-100 \%$ solvent A (4-15 $\mathrm{min}), 100 \%$ solvent A (15-18 $\mathrm{min})$, and 100-5\% solvent A (18-25 min) to recover initial conditions. Melatonin was recorded using multiple reaction monitoring (MRM) mode by selecting ion $233\left([\mathrm{M}+\mathrm{H}]^{+}\right)$at the first quadrupole (Q1), fragmented in Q2, and analysing the resulting ion $\mathrm{m} / \mathrm{z} 130$, 131,159 , and 174 at Q3, measuring at 174 . Quantification was performed by the external standard 
method, using pure melatonin (Sigma-Aldrich Química, Madrid, Spain) dissolved in $\mathrm{MeOH} / \mathrm{H}_{2} \mathrm{O}$ $(80: 20, v / v)$ containing $0.1 \%$ formic acid. Melatonin content was expressed as $\mathrm{ng} \mathrm{mg}^{-1}$ CSE.

2.3.4. CGA and Caffeine Quantification by Ultra-Performance Liquid Chromatography-Electrospray Ionization tandem Mass Spectrometry (UPLC-ESI-MS/MS)

CGA and caffeine were determined by UPLC-ESI-MS/MS. CSE dissolved in Milli-Q water (10 mg $\mathrm{mL}^{-1}$ ) was filtered using a $0.45 \mu \mathrm{m}$ pore-size nylon membrane syringe filter (Análisis Vínicos, Tomelloso, Spain). Aliquots $(10 \mu \mathrm{L})$ were analysed using an Accela liquid chromatograph (Thermo Scientific, San Jose, CA, USA) coupled to a TSQ Quantum ${ }^{\mathrm{TM}}$ (Thermo Scientific, San Jose, CA, USA) triple quadrupole analyser via an electrospray ionisation (ESI) interface. The mass spectrometer was operated in the positive ESI mode to quantify caffeine and in the negative ESI mode to quantify CGA. Two transition ions were monitored for identification, but only the most intense one for each precursor ion was used for quantification. Parent $\left([\mathrm{M}-\mathrm{H}]^{-}\right)$and product ions for CGA were $\mathrm{m} / \mathrm{z} 353.2$ and 191.1, respectively, whereas parent $\left([\mathrm{M}-\mathrm{H}]^{+}\right)$and product ions for caffeine were $\mathrm{m} / z 195.1$ and 138.2,

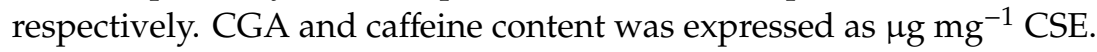

\subsubsection{In Vitro Antioxidant Capacity}

The antioxidant capacity of samples was estimated by the $\mathrm{ABTS}^{\bullet+}$ decolourisation assay, as previously described [23]. 2.2'-Azino-bis(3-ethylbenzothiazoline-6-sulfonic) acid radical cations $\left(\mathrm{ABTS}^{\bullet+}\right.$ ) were produced by reacting $7 \mathrm{mmol} \mathrm{L}^{-1} \mathrm{ABTS}$ stock solution with $2.45 \mathrm{mmol} \mathrm{L}^{-1}$ potassium persulfate and allowing the mixture to stand in the dark at room temperature for 12-16 $\mathrm{h}$ before use. The $\mathrm{ABTS}^{\bullet+}$ solution (stable for two days) was diluted in $5 \mathrm{mmol} \mathrm{L}^{-1}$ phosphate buffer (PBS) $\mathrm{pH} 7.4$ to an absorbance of $0.70 \pm 0.02$ at $734 \mathrm{~nm}$. Each sample was dissolved in PBS $\left(5 \mathrm{mmol} \mathrm{L}^{-1}\right.$, $\mathrm{pH} 7.4$ ) at $0.1 \mathrm{mg} \mathrm{L}^{-1}$. Thirty $\mu \mathrm{L}$ of the test sample and $200 \mu \mathrm{L}$ of diluted $\mathrm{ABTS}^{\bullet+}$ solution were mixed. The absorbance of the samples at $734 \mathrm{~nm}$ was measured at $10 \mathrm{~min}$ of reaction using a BioTek Power Wave ${ }^{\mathrm{TM}} \mathrm{XS}$ microplate reader. CGA at concentrations of $0.015-0.2 \mathrm{mmol} \mathrm{L}^{-1}$ was used for calibration, and results were expressed as $\mu \mathrm{g}$ CGA equivalents $\mathrm{mg}^{-1}\left(\mu \mathrm{g}\right.$ CGAE $\left.\mathrm{mg}^{-1}\right)$.

\subsection{Maillard Reaction In Vitro Models: Protein Glycation and Formation of Methylglyoxal-Derivate AGE}

Two Maillard reaction model systems were prepared to investigate the effect of pure phytochemicals and CSE. The different model systems were employed for evaluating the effect of the phytochemicals on the glycation (BSA-glucose (BSA-GLU) model system) and glycoxidation (BSA-MGO) reactions. The former provided information on the effect of the phytochemicals on the different steps of the Maillard reaction, including Amadori rearrangement (early stage), while the latter provided information on the trapping of carbonyl groups and formation of advanced products of the Maillard reaction and protein oxidation products. Before the initiation of the glycation or glycoxidation reactions by the addition of glucose or $\mathrm{MGO}$, the $\mathrm{pH}$ values of all solutions were measured at $25^{\circ} \mathrm{C}$ using an electrode $\mathrm{pH}$-meter (Metler Toledo, Madrid, Spain) to ensure optimal and equal conditions of reaction in all samples ( $\mathrm{pH}=7.4$ ). All samples were prepared in triplicate. A control solution of BSA alone was also included.

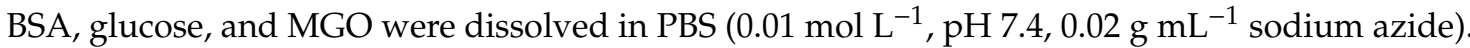
BSA was mixed with glucose and incubated at $37^{\circ} \mathrm{C}$ for 21 days in the absence or presence of inhibitors (aminoguanidine, CSE, CGA, genistein, and melatonin). In parallel, inhibitors were incubated with BSA at $37^{\circ} \mathrm{C}$ for 21 days to measure their intrinsic fluorescence. Likewise, BSA was mixed with MGO and incubated at $37^{\circ} \mathrm{C}$ for $72 \mathrm{~h}$. The final concentration of the reactants was $10 \mathrm{mg} \mathrm{mL}^{-1} \mathrm{BSA}(150 \mu \mathrm{mol}$ $\left.\mathrm{L}^{-1}\right), 100 \mathrm{mg} \mathrm{mL}^{-1}$ glucose, $5 \mathrm{mmol} \mathrm{L}^{-1} \mathrm{MGO}, 5 \mathrm{mmol} \mathrm{L}^{-1}$ aminoguanidine, genistein, and melatonin and 1,5 , or $10 \mathrm{mmol} \mathrm{L}^{-1}$ CGA.

The progress of the protein glycation reaction was determined by analysing free amino groups, fructosamine, fluorescent and total AGE, and protein carbonyls. The progress of the formation of MGO-derivative AGE was determined by analysing free amino groups, fluorescent AGE, and protein carbonyls. 


\subsection{Assessment of the Degree of Progress of the Maillard Reaction}

\subsubsection{Free Amino Groups}

Free protein amino groups (both $\mathrm{N}$-terminal and epsilon $-\mathrm{NH}_{2}$ of lysine) were determined by the OPA assay. The OPA reagent was freshly prepared by dissolving $10 \mathrm{mg}$ of OPA in $250 \mu \mathrm{L}$ of 95\% (v/v) ethanol and adding $9.8 \mathrm{~mL}$ of $0.01 \mathrm{~mol} \mathrm{~L}^{-1} \mathrm{PBS} \mathrm{pH} 7.4$ and $20 \mu \mathrm{L}$ of $\beta$-mercaptoethanol. The reaction mixture was composed of $10 \mu \mathrm{L}$ of the sample, containing $1 \mathrm{mg} \mathrm{mL}^{-1}$ of protein, $100 \mu \mathrm{L}$ of OPA reagent, and $140 \mu \mathrm{L}$ of Milli-Q water. The reaction was carried out in a transparent polystyrene 96-well microtest plate (No. 82.1581). Fluorescence was measured after the addition of the OPA reagent on a microplate fluorescence reader Biotek Synergy ${ }^{\mathrm{TM}}$ HT (Biotek Instruments, Winooski, VT, USA) using $360 \pm 40 \mathrm{~nm}$ and $460 \pm 40 \mathrm{~nm}$ as excitation and emission wavelengths. Fluorescence was measured every $53 \mathrm{~s}$ for $15 \mathrm{~min}$. Calibration curves were constructed using standard solutions of $N_{\alpha}$-acetyl-L-lysine $\left(0.025-1 \mathrm{mmol} \mathrm{L}^{-1}\right)$. All measurements were performed in triplicate, and data were expressed as $\mu \mathrm{g} N_{\alpha}$-acetyl-L-lysine equivalent per $\mathrm{mg}$ of protein ( $\mu \mathrm{g} \mathrm{mg}^{-1}$ prot.).

\subsubsection{Early Products of the Maillard Reaction}

The formation of Amadori compounds was measured by the NBT assay, as previously described [24]. Briefly, samples $(25 \mu \mathrm{L})$ were added to sodium carbonate buffer $\left(100 \mu \mathrm{L}, 100 \mathrm{mmol} \mathrm{L}^{-1}\right.$, $\mathrm{pH} 10.8)$ with NBT $\left(0.25 \mathrm{mmol} \mathrm{L}{ }^{-1}\right)$. Microplates were incubated for $20 \mathrm{~min}$ at $37^{\circ} \mathrm{C}$ and measured spectrophotometrically against control at $530 \mathrm{~nm}$. The fructosamine analogue DMF was used as a standard. All measurements were performed in triplicate and expressed as $\mu \mathrm{g}$ DMF equivalents $\mathrm{mg}^{-1}$ protein ( $\mu$ g DMF eq. $\mathrm{mg}^{-1}$ prot.).

\subsubsection{Fluorescent AGE}

AGE formation was monitored by fluorescence spectrophotometry using a Biotek microplate spectrophotometer set at $360 \pm 40 \mathrm{~nm}$ and $460 \pm 40 \mathrm{~nm}$ as excitation and emission wavelengths. All measurements were performed in triplicate and expressed as relative fluorescence units $\mathrm{mg}^{-1}$ protein (RFU $\mathrm{mg}^{-1}$ prot.).

\subsubsection{Total AGE}

The content of total AGE was analysed by Enzyme-Linked Immuno Sorbent Assay (ELISA) using a commercial kit, according to the manufacturer's instructions (Lamider, México). A total of $100 \mu \mathrm{L}$ of standard or sample was pipetted to each well (coated with an AGE-sensitive primary antibody), and $50 \mu \mathrm{L}$ of the conjugate (peroxidase bound secondary antibody, primary antibody sensitive) was added. After incubation at $25^{\circ} \mathrm{C}$ for at least $30 \mathrm{~min}$, the wells were washed three times with $300 \mu \mathrm{L}$ of the provided buffer. Then, $100 \mu \mathrm{L}$ of the substrate-chromogen solution (10 mg OPD, $100 \mu \mathrm{L} \mathrm{H}_{2} \mathrm{O}_{2} 3.7 \%$ $v / v, 11 \mathrm{~mL}$ buffer) was re-incubated for $30 \mathrm{~min}$ (exactly). Finally, $20 \mu \mathrm{L}$ of the stop solution $\left(1 \mathrm{~mol} \mathrm{~L}^{-1}\right.$ $\mathrm{H}_{2} \mathrm{SO}_{4}$ ) was added. Absorbance was read at 492 and $530 \mathrm{~nm}$. All measurements were performed in triplicate. The calculations were performed using logistic transformation, and the results were expressed as relative fluorescence units $\mathrm{mg}^{-1}$ protein (RFU mg ${ }^{-1}$ prot.).

\subsubsection{Protein Oxidation}

Protein oxidation or glycoxidation was measured as carbonyl groups content according to an adapted method described previously [25]. A total of $50 \mu \mathrm{L}$ of the sample was derivatised with four volumes $(200 \mu \mathrm{L})$ of DNPH $\left(10 \mathrm{mmol} \mathrm{L}^{-1}\right.$ 2,4-dinitrophenylhydrazine in $\left.2 \mathrm{~mol} \mathrm{~L}^{-1} \mathrm{HCl}\right)$. In parallel, a blank of each sample was made along with each sample, using $200 \mu \mathrm{L}$ of $2 \mathrm{~mol} \mathrm{~L}{ }^{-1} \mathrm{HCl}$. The samples were kept in the dark and under gentle agitation $(400 \mathrm{rpm})$ for $1 \mathrm{~h}$. Once derivatised, the protein samples were precipitated with $250 \mu \mathrm{L}$ of TCA $(20 \% \mathrm{~m} / \mathrm{v})$ and kept on ice for $30 \mathrm{~min}$. Then, samples were centrifuged $(7000 \times g, 5 \mathrm{~min})$ and pellets were washed with ethanol: ethyl acetate (50:50, 
$v / v)$ at least three times, to eliminate the remaining and non-reacted DNPH, and re-dissolved in 6 mol L ${ }^{-1}$ guanidine (prepared in $50 \mathrm{mmol} \mathrm{L}^{-1}$ phosphate buffer, $\mathrm{pH}$ 2.5). Absorbance was measured at $360 \mathrm{~nm}$. Carbonyl content was expressed as nmol mg ${ }^{-1}$ protein using an extinction coefficient of $22,000 \mathrm{nmol} \mathrm{L}^{-1} \mathrm{~cm}^{-1}$. Protein concentration was determined by the Bradford method.

\subsection{Evaluation of the Formation of Protein-Phytochemical Complexes}

Before analysis, the protein fraction of samples was isolated by ultrafiltration. Samples $(0.4 \mathrm{~mL})$ were placed in the sample reservoir of an Amicon ${ }^{\circledR}$ Ultra $0.5 \mathrm{~mL}$ centrifugal filter unit fitted with an Ultracel ${ }^{\circledR} 30 \mathrm{~K}$ regenerated cellulose membrane (30 kDa cut-off) (Millipore Ltd., Tullagreen, Ireland) and centrifuged at $14,000 \times g$ for $40 \mathrm{~min}$ at room temperature. The retentates were recovered and diluted in PBS $(0.4 \mathrm{~mL})$. Protein concentration was determined by the Bradford micromethod. The high molecular weight (HMW) protein fraction was used for structural and functional characterisation.

\subsubsection{UV-Vis Spectra}

A Biotek microplate UV-Vis spectrophotometer equipped with UV KC junior software (Biotek) was used. The spectrum of the isolated protein fraction was measured at 200-790 nm using a quartz 96-well microplate. The results were expressed as absorbance units (AU).

\subsubsection{Antioxidant Capacity of the Protein-Phytochemical Complexes}

The antioxidant capacity of samples' protein fractions was estimated by the ABTS ${ }^{\bullet+}$ decolourisation assay, as previously described in Section 2.3.5.

\subsubsection{Fluorescence Spectra}

Fluorescence spectra measurements of the protein solutions were obtained with a Tecan Infinite 200 Pro fluorometer (Männedorf, Switzerland). There was no significant absorption/emission from the added molecules at the excitation wavelength $(250 \mathrm{~nm})$. Therefore, the observed fluorescence signal $(F)$ was identified as the fluorescence contributed only by the tryptophan residue of the protein. All the data reported here are the average of three independent measurements. The protein fluorescence quenching data in the presence of CGA, genistein, and melatonin (quenchers, Q) was analysed with the Stern-Volmer equation:

$$
\frac{F_{0}}{F}=1+K_{S V}[Q]=1+k_{q} \tau_{0}[Q],
$$

where $F_{0}$ and $F$ represent the protein fluorescence in the absence and presence of quencher at concentration [Q], respectively. $K_{S V}$ is the Stern-Volmer quenching constant, $k_{q}$ is the bimolecular quenching constant, and $\tau_{0}$ is the intrinsic tryptophan fluorescence lifetime $\left(\sim 5.78 \times 10^{-9} \mathrm{~s}\right)$ in the absence of quencher. For the static quenching interaction, when small molecules bind independently to a set of equivalent sites on a macromolecule, the binding constant $\left(K_{a}\right)$ and the number of binding sites $(n)$ can be determined by the following equation:

$$
\log \frac{\left(F_{0}-F\right)}{F}=\log K_{a}+n \log [Q],
$$

where, $F_{0}, F$, and $[Q]$ are the same as in the previous equation, $K_{a}$ is the binding constant, and $n$ is the number of binding sites per BSA molecule.

\subsubsection{In Silico Prediction of Protein-Phytochemical Interaction}

In silico studies were performed using molecular docking methods to investigate the interactions of glucose, MGO, CGA, genistein, and melatonin with the different domains of BSA. The 3D crystal structure of BSA (PDB ID: 3V03) was downloaded from the Research Collaboratory for Structural Bioinformatics (RCSB) Protein Data Bank website (http://www.rcsb.org/pdb/home/home.do). 
Search space dimensions, centre point, and flexible torsions were assigned with AutoDock Tools, and the docking calculations were carried out using AutoDock Vina according to previous studies [26-28]. Water molecules in the BSA structure were removed, hydrogen atoms were added, and partial charges were assigned to the macromolecule. The structure of BSA was divided into three domains, I, II, and III, each subdivided into two subdomains, A and B. Compound structures were retrieved from the PubChem Compound database (https://pubchem.ncbi.nlm.nih.gov/). One hundred different runs were performed for each ligand, and the pose with the highest binding affinity (lowest binding energy) was saved. Protein-ligand interactions and binding modes were visualised in the Discovery Studio 2017 R2 Client (Dassault Systèmes Biovia Corp ${ }^{\circledR}$, San Diego, CA, USA).

\subsection{Statistical Analysis}

Experiments were performed in triplicate. The analysis of each chemical indicator was also carried out in triplicate. Results were expressed as mean \pm standard deviation (SD) $(n=3)$ and analysed by one-way analysis of variance (ANOVA) and post hoc Tukey test. Differences were considered significant at $p<0.05$. Bivariate correlation analyses to study the associations between results from different experiments were performed. To analyse the similarities among the antiglycative potentials of the samples, principal component analysis (PCA) and hierarchical cluster analysis (dendrogram) were accomplished. The statistical analysis of the results was performed using SPSS 23.0 (IBM, Armonk, NY, USA). Multivariate analyses were carried out with XLSTAT 2016 for Microsoft Excel 2016 (Addinsoft, Paris, France).

\section{Results}

\subsection{Characterisation of CSE}

The compositions of phytochemicals and the overall antioxidant capacity of CSE are shown in Table 1. The presence of phenolic compounds, CGA, flavonoids, melatonin, and caffeine was detected. Phenolic compounds and caffeine are the most abundant compounds among those analysed in the extract. It is worth noting the presence of melatonin $\left(2.0 \mathrm{ng} \mathrm{mg}^{-1}\right)$ in CSE. CGA $\left(35.1 \mu \mathrm{g} \mathrm{mg}^{-1}\right)$ represents about $50 \%$ of the total phenolic compounds, but flavonoids, including isoflavones, also have a significant role $\left(83.2 \mu \mathrm{g} \mathrm{RE} \mathrm{mg}{ }^{-1}\right)$ on the phytochemical load of CSE. The extract presented antioxidant capacity in values corresponding to the expected contribution of the studied phytochemicals.

Table 1. Phytochemical characterisation of the coffee silverskin extract (CSE), including total phenolic compounds (TPC), chlorogenic acid (CGA), total flavonoid content (TFC), melatonin, caffeine, and antioxidant capacity measured by the $\mathrm{ABTS}^{\bullet+}$ method.

\begin{tabular}{cc}
\hline Phytochemicals & Concentration (mean \pm SD) \\
\hline TPC $\left(\mu \mathrm{g} \mathrm{CGAE} \mathrm{mg}{ }^{-1}\right.$ extract $)$ & $70.4 \pm 4.2$ \\
CGA $\left(\mu \mathrm{g} \mathrm{mg}^{-1}\right.$ extract $)$ & $35.1 \pm 0.7$ \\
TFC $\left(\mu \mathrm{g} \mathrm{RE} \mathrm{mg}{ }^{-1}\right.$ extract $)$ & $83.2 \pm 4.3$ \\
Melatonin $\left(\mathrm{ng} \mathrm{mg}^{-1}\right.$ extract $)$ & $2.0 \pm 0.1$ \\
Caffeine $\left(\mu \mathrm{g} \mathrm{m}^{-1}\right.$ extract $)$ & $47.0 \pm 0.5$ \\
$\mathrm{ABTS}^{\bullet+}\left(\mu \mathrm{g} \mathrm{CGAE} \mathrm{mg}{ }^{-1}\right.$ extract $)$ & $166.5 \pm 1.8$ \\
\hline
\end{tabular}

\subsection{Inhibition of the Maillard Reaction}

\subsubsection{Protein Glycation in the BSA-GLU Model System}

Figure 1 shows the progress of the reaction between protein and glucose at $\mathrm{pH} 7.4,37^{\circ} \mathrm{C}$ for 21 days, in the presence and absence of phytochemicals. A significant $(p<0.05)$ loss of amino groups was observed in the control positive sample (GLU), which denoted the reaction (Figure 1A). CGA and genistein at concentrations higher than $5 \mathrm{mmol} \mathrm{L}^{-1}$ significantly decreased $(p<0.05)$ the content of 
free amino groups. CGA samples showed a dose-response effect in the content of amino groups being inversely proportional to CGA concentration $(r=-0.976)$. CSE also produced a significant $(p<0.05)$ decrease in amino groups. Free amino groups' values found in samples composed by aminoguanidine and melatonin were not significantly different $(p>0.05)$ to those detected in the control samples (BSA in the presence and absence of glucose).
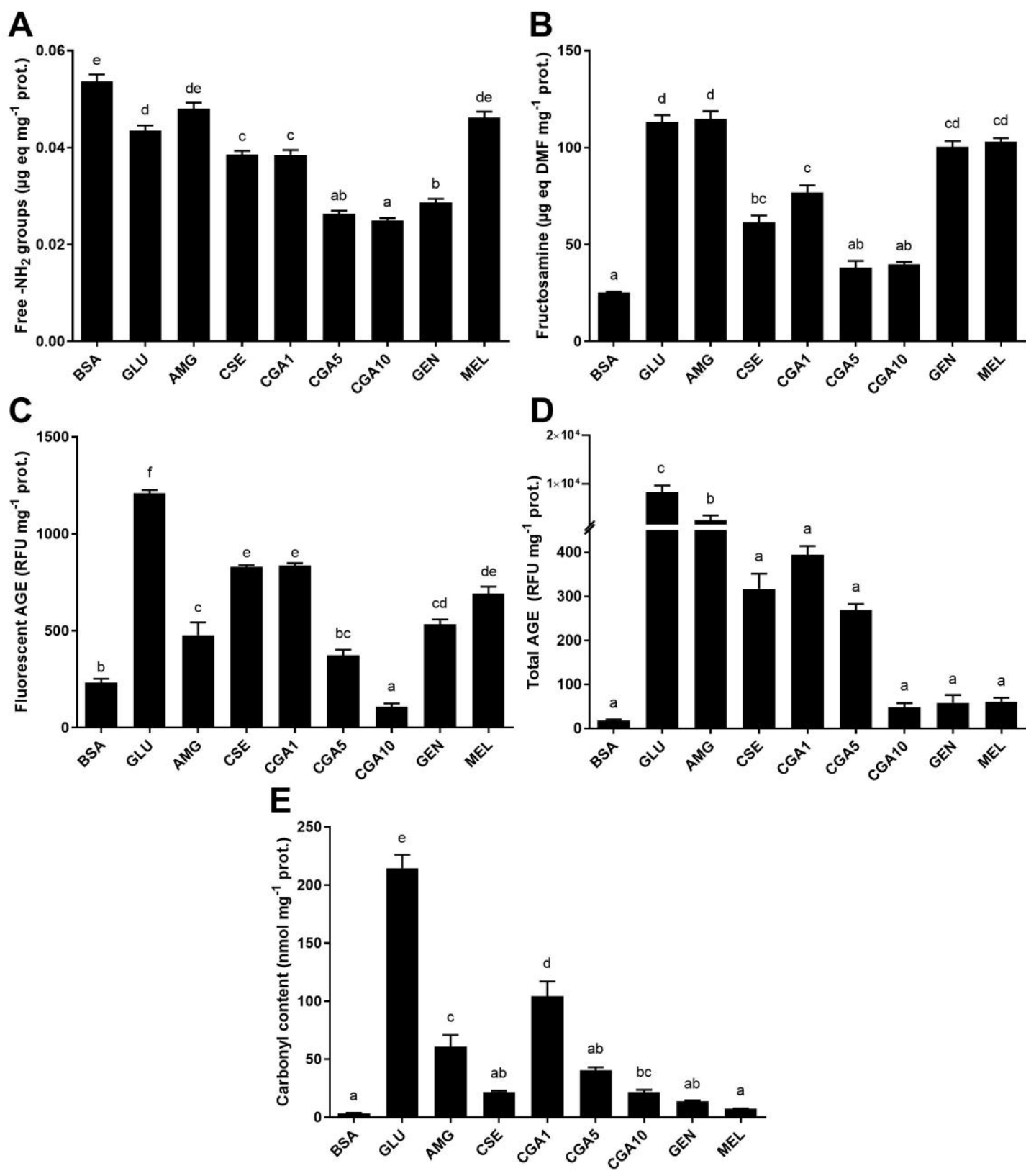

Figure 1. Contents of free amino groups (A), fructosamine (B), fluorescent AGE (C), total AGE (D), and protein oxidation (E) in the samples of the BSA-GLU glycation system $\left(21\right.$ days incubation, $37^{\circ} \mathrm{C}, \mathrm{pH}$ 7.4). BSA: negative control; GLU: BSA + glucose; AMG: BSA + glucose + aminoguanidine; CSE: BSA + glucose + CSE $\left(12,5 \mathrm{mg} \mathrm{mL}^{-1}\right)$; CGA1: BSA + glucose + 1 mmol L ${ }^{-1}$ CGA; CGA5: BSA + glucose + 5 mmol $\mathrm{L}^{-1}$ CGA; CGA10: BSA + glucose $+10 \mathrm{mmol} \mathrm{L}{ }^{-1}$ CGA; GEN: BSA + glucose +5 mmol L ${ }^{-1}$ genistein; MEL: $\mathrm{BSA}+$ glucose $+5 \mathrm{mmol} \mathrm{L}^{-1}$ melatonin. Results are presented as mean $\pm \mathrm{SD}(n=3)$. Bars with different letters denote significant differences $(p<0.05)$ when subjected to the Tukey multiple range test.

As expected, the formation of early Maillard reaction products, also called Amadori rearrangement compounds, was detected in the reaction mixture (Figure 1B). Their formation was significantly inhibited 
$(p<0.05)$ by the addition of CSE and CGA at high concentrations ( 5 and $\left.10 \mathrm{mmol} \mathrm{L}^{-1}\right)$. Aminoguanidine, genistein, and melatonin did not inhibit the early step of the Maillard reaction.

Figure 1C shows the formation of fluorescent AGE. As can be observed, the addition of glucose produced a significant $(p<0.05)$ formation of fluorescent compounds. Their formation was significantly $(p<0.05)$ inhibited in the presence of aminoguanidine. CSE and $1 \mathrm{mmol} \mathrm{L}^{-1}$ CGA also significantly inhibited their formation (51 and 50\%, respectively). A dose-response relationship between CGA concentration and fluorescent AGE formation was detected $(r=-0.976)$. CGA, genistein, and melatonin at a concentration of $5 \mathrm{mmol} \mathrm{L}^{-1}$ showed effective inhibition of the formation of fluorescent compounds in the glycation mixtures. The inhibitory effect of genistein was comparable to that of aminoguanidine and melatonin $(p>0.05)$. Melatonin presented similar inhibition to that observed for $1 \mathrm{mmol} \mathrm{L}^{-1} \mathrm{CGA}$, genistein, and CSE $(p>0.05)$.

Total AGE contents are shown in Figure 1D. A large formation of AGE was significantly inhibited by the addition of all the studied phytochemicals $(95-100 \%, p<0.05)$. As described for fluorescent AGE, a dose-response effect was noted for CGA $(r=-0.996)$. Genistein, $10 \mathrm{mmol} \mathrm{L}^{-1} \mathrm{CGA}$, and melatonin were the most effective inhibitors of total AGE formation among the studied phytochemicals $(p<0.05)$. The addition of CSE in the glycation mixture significantly inhibited the formation of fluorescent compounds $(p<0.05)$.

Figure $1 \mathrm{E}$ shows the content of protein carbonyls due to oxidation during the glycation reaction. This formation was enhanced 600-fold in the presence of glucose. The addition of aminoguanidine, phytochemicals, and coffee by-product extract significantly inhibited $(p<0.05)$ the formation of carbonyls bound to BSA. CSE (92\%), genistein (95\%), and melatonin (98\%) showed the highest capacity to inhibit the carbonyl content formation amount the studied samples. CGA $\left(1 \mathrm{mmol} \mathrm{L}^{-1}\right)$ had a lower effect for inhibiting the formation of protein carbonyls, followed by aminoguanidine. A dose-response inhibitory effect was observed for CGA. At higher concentrations (5 and $10 \mathrm{mmol} \mathrm{L}^{-1}$ CGA), the inhibition was similar $(p<0.05)$ to that of CSE, genistein, and melatonin.

Figure 2 illustrates the modifications of the HMW protein fraction $(>30 \mathrm{kDa})$ isolated after the incubation with glucose. The BSA UV-Vis spectrum (Figure 2A) was unaffected by the addition of glucose and aminoguanidine. However, the presence of CSE, CGA, genistein, and melatonin in the reaction mixture produced changes in the UV-Vis spectrum of the protein. An absorbance maximum was detected at $270-280 \mathrm{~nm}$ in all samples treated with phytochemicals. BSA antioxidant properties (Figure 2B) were not modified in the presence of glucose or aminoguanidine. However, the addition of pure phytochemicals and CSE resulted in the formation of protein-phytochemical complexes which possessed antioxidant properties. The antioxidant properties of the protein-phytochemical

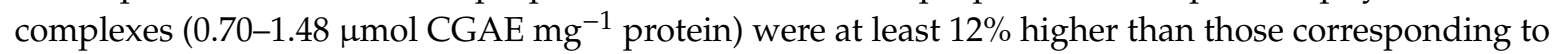
the native BSA.

PCA was carried out to find out the relationship between phytochemicals and antiglycative effects (Figure 3A). Six main principal components (PC) were obtained; the first two represented 76.3\% of the total variability. PC1 separated the samples into two groups: samples treated with CSE or phytochemicals, along with BSA control, and samples treated with glucose and with aminoguanidine or CGA at the lowest concentration $\left(1 \mathrm{mmol} \mathrm{L}^{-1}\right)$. PC2 separated the samples into those treated with genistein or melatonin, and those treated with CGA (5 and $\left.10 \mathrm{mmol} \mathrm{L}^{-1}\right)$ and control (BSA). The sample treated with CSE presented intermediate values located between the two groups. For PC1, the content of total AGE and carbonyls were the dominant variables in the separation of samples treated with pure phytochemicals or CSE, and samples not treated or treated with aminoguanidine or $1 \mathrm{mmol} \mathrm{L}{ }^{-1}$ CGA. PC2 correlated mainly with the antioxidant capacity (ABTS) of the samples. It is worth emphasising that the content in AGE, carbonyls, and free amino groups was negatively correlated with the antioxidant capacity. Figure 3B shows the dendrogram of the natural grouping of samples according to their antiglycative potential. As observed, the samples were organised into two groups, one formed by two subgroups, clustering the systems consisting of $1 \mathrm{mmol} \mathrm{L}^{-1}$ CGA and CSE $\left(12.5 \mathrm{mg} \mathrm{mL}^{-1}\right)$ and melatonin and aminoguanidine (both $5 \mathrm{mmol} \mathrm{L}^{-1}$ ), respectively. The second 
cluster grouped those samples with the highest antiglycative capacity, corresponding to the systems constituted by CGA ( 5 and $\left.10 \mathrm{mmol} \mathrm{L}^{-1}\right)$ and by genistein $\left(5 \mathrm{mmol} \mathrm{L}^{-1}\right)$.
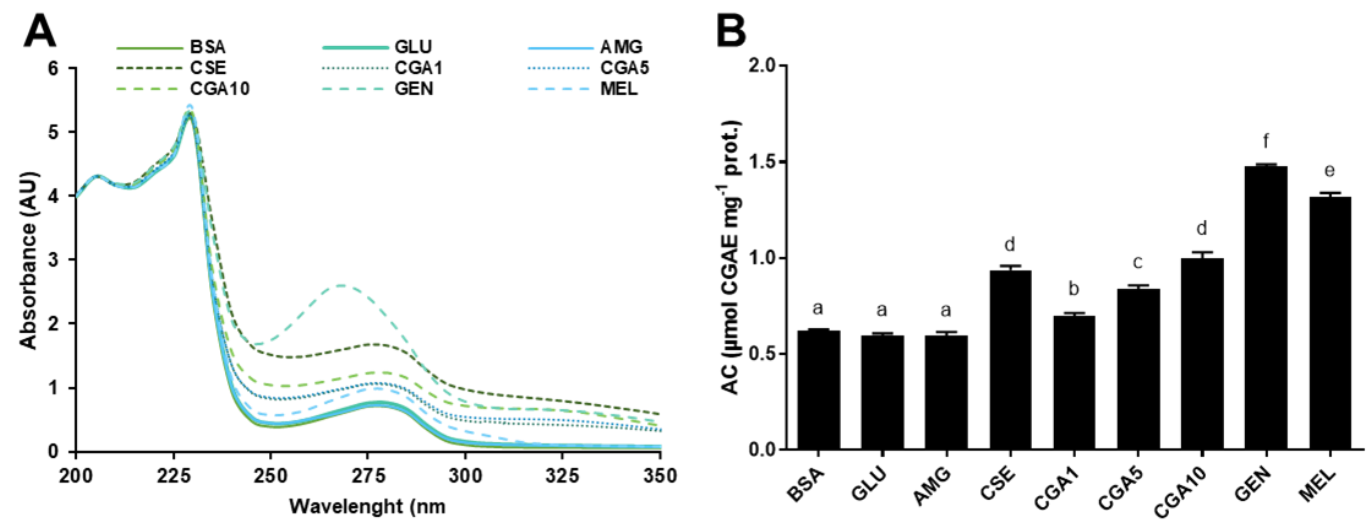

Figure 2. UV-Vis spectra (A) and antioxidant capacities (B) of the high molecular weight protein fractions $(>30 \mathrm{kDa})$ isolated from the samples of the BSA-GLU glycation system (21 days incubation, $37^{\circ} \mathrm{C}$, pH 7.4) BSA: negative control; GLU: BSA + glucose; AMG: BSA + glucose + aminoguanidine; CSE: BSA + glucose + CSE $\left(12,5 \mathrm{mg} \mathrm{mL}^{-1}\right)$; CGA1: BSA + glucose + 1 mmol L ${ }^{-1}$ CGA; CGA5: BSA + glucose + 5 mmol L ${ }^{-1}$ CGA; CGA10: BSA + glucose + $10 \mathrm{mmol} \mathrm{L}^{-1}$ CGA; GEN: BSA + glucose + $5 \mathrm{mmol} \mathrm{L}{ }^{-1}$ genistein; MEL: BSA + glucose $+5 \mathrm{mmol} \mathrm{L}^{-1}$ melatonin. Results are presented as mean \pm $\mathrm{SD}(n=3)$. Bars with different letters denote significant differences $(p<0.05)$ when subjected to Tukey multiple range test.
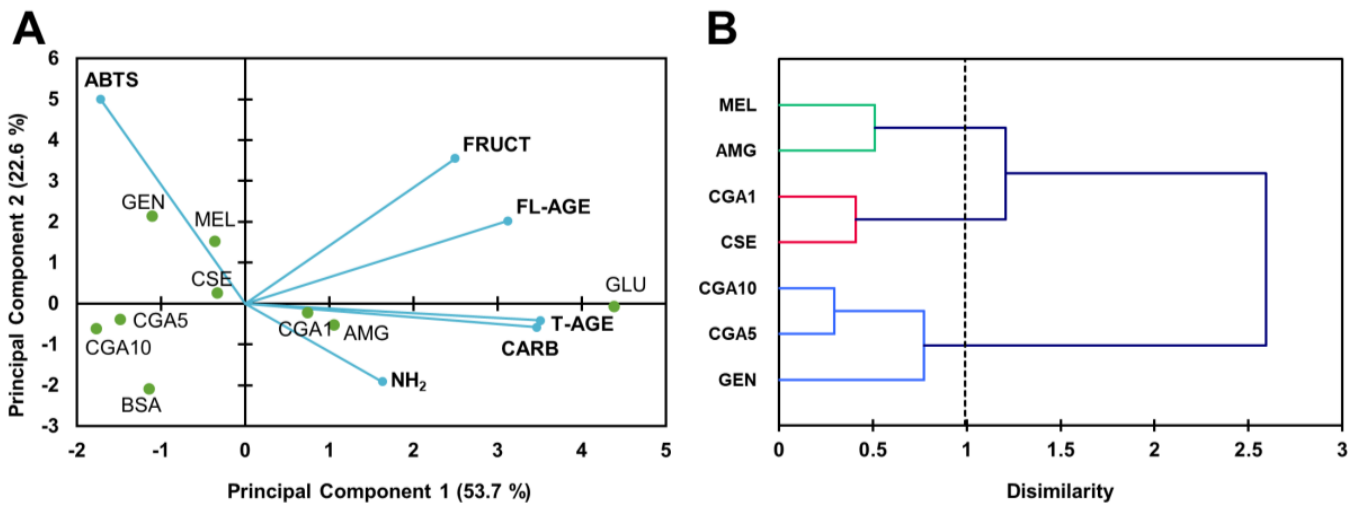

Figure 3. Biplot (scores of samples and load factors of each variable) of the principal component analysis (PCA) (A), including the content of free amino groups $\left(\mathrm{NH}_{2}\right)$, fructosamine (FRUCT), fluorescent AGE (FL-AGE), total AGE (T-AGE), and protein carbonyls (CARB), and dendrogram of hierarchical cluster analysis of the glycation inhibitory activity $(\mathbf{B})$ of the samples of the BSA-GLU glycation system (21 days agitation, $37^{\circ} \mathrm{C}, \mathrm{pH}$ 7.4) BSA: negative control; GLU: BSA + glucose; AMG: BSA + glucose + aminoguanidine; CSE: BSA + glucose + CSE $\left(12,5 \mathrm{mg} \mathrm{mL}^{-1}\right)$; CGA1: $\mathrm{BSA}+$ glucose $+1 \mathrm{mmol} \mathrm{L}^{-1}$ CGA; CGA5: BSA + glucose + 5 mmol L ${ }^{-1}$ CGA; CGA10: BSA + glucose + $10 \mathrm{mmol} \mathrm{L}^{-1}$ CGA; GEN: $\mathrm{BSA}+$ glucose $+5 \mathrm{mmol} \mathrm{L}^{-1}$ genistein; MEL: BSA + glucose $+5 \mathrm{mmol} \mathrm{L}^{-1}$ melatonin .

Significant positive correlations $(r \geq 0.5 ; p<0.01)$ were observed between the content of fluorescent AGE, total AGE, fructosamine, and protein carbonyls. Also, a correlation was observed between the concentration of total AGE, fructosamine, and carbonyls. The antioxidant capacity was negatively correlated $(p<0.05)$ with the free amino group content and carbonyl content. The inhibition of fructosamine and AGE formation (both fluorescent and total) negatively correlated with the inhibition of free amino groups' loss $(r \geq-0.6 ; p<0.01)$. 


\subsubsection{MGO-Derivative AGE Formation in the BSA-MGO Model System}

The results obtained on the formation of MGO-derivative AGE are shown in Figure 4. The content of free amino groups (Figure $4 \mathrm{~A})$ was significantly $(p<0.05)$ decreased $(60 \%)$, suggesting the reaction of MGO with the protein. Only aminoguanidine and melatonin $\left(5 \mathrm{mmol} \mathrm{L}^{-1}\right)$ inhibited the loss of free amino groups significantly $(p<0.05)$. Treatment with genistein further decreased $(90 \%)$ the content of free amino groups. It should be pointed out that the content of amino groups in CGA samples showed a dose-response effect, inversely proportional to CGA concentration $(r=-0.999)$. The content of fluorescent AGE (Figure 4B) was significantly $(p<0.05)$ increased, approximately 10 -fold in the sample treated with MGO. The phytochemicals significantly $(p<0.05)$ inhibited the formation of fluorescent AGE. The rate of inhibition was within 30-100\%, with melatonin the less active and genistein the most effective compound. A strong linear correlation was observed between CGA concentration and the inhibition of the formation of fluorescent AGE $(r=0.917)$. Protein carbonyl content (Figure 4C) increased with MGO treatment. Aminoguanidine, genistein, melatonin, and CSE significantly $(p<0.05)$ inhibited protein oxidation. CSE and genistein inhibited $41 \%$, while melatonin was more effective (59\%). However, CGA seemed to promote such processes, with linearly correlated protein oxidation and CGA concentration $(r=0.948)$.

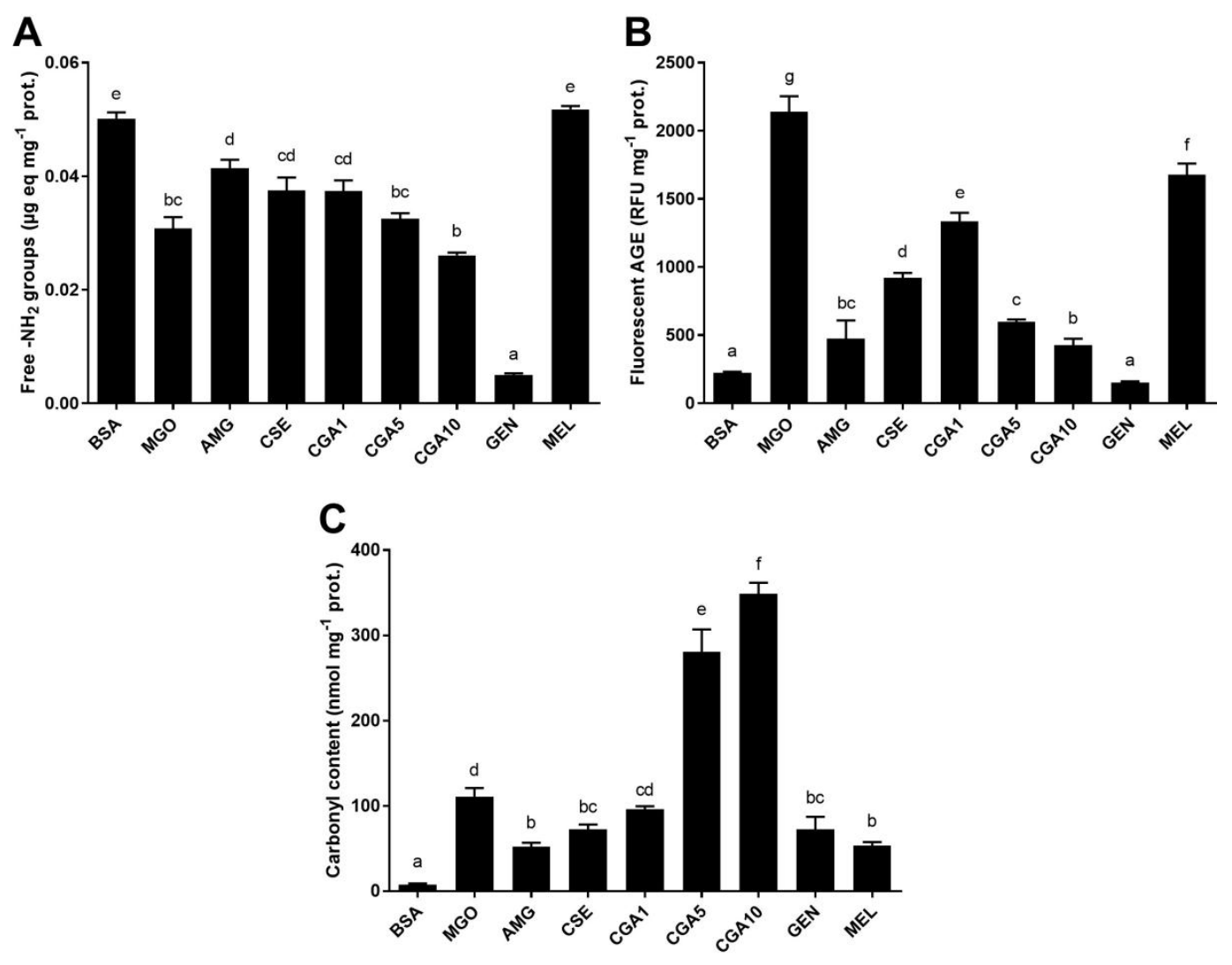

Figure 4. Contents of free amino groups (A), fluorescent AGE (B), and protein carbonyls (C) in the samples of the BSA-MGO (methylglyoxal) glycation system $\left(72 \mathrm{~h}\right.$ incubation, $37{ }^{\circ} \mathrm{C}, \mathrm{pH}$ 7.4) BSA: negative control; MGO: BSA + methylglyoxal; AMG: BSA + methylglyoxal + aminoguanidine; CSE: BSA + methylglyoxal + CSE $\left(12,5 \mathrm{mg} \mathrm{mL}^{-1}\right)$; CGA1: BSA + methylglyoxal + $1 \mathrm{mmol} \mathrm{L}^{-1}$ CGA; CGA5: $\mathrm{BSA}+$ methylglyoxal $+5 \mathrm{mmol} \mathrm{L}^{-1}$ CGA; CGA10: BSA + methylglyoxal + $10 \mathrm{mmol} \mathrm{L}^{-1}$ CGA; GEN: $\mathrm{BSA}+$ methylglyoxal $+5 \mathrm{mmol} \mathrm{L}^{-1}$ genistein; MEL: BSA + methylglyoxal $+5 \mathrm{mmol} \mathrm{L}^{-1}$ melatonin. Results are presented as mean \pm SD $(n=3)$. Bars with different letters denote significant differences $(p<0.05)$ when subjected to the Tukey multiple range test. 
Figure 5 shows the modifications occurring in the HMW fraction of BSA treated with MGO in the presence or absence of the tested inhibitors. Structural modifications appeared not to be very noticeable for the treatments with aminoguanidine or $10 \mathrm{mmol} \mathrm{L}^{-1}$ CGA (Figure 5A). CGA at 1 and $5 \mathrm{mmol} \mathrm{L}^{-1}$ prevented the modifications caused by MGO. However, genistein and melatonin produced remarkable modifications in the native protein spectrum, with absorbance increased at $270-280 \mathrm{~nm}$. The antioxidant capacity of the samples (Figure 5B), which indicates whether protein-phytochemical complexes were formed, demonstrated a significant $(p<0.05)$ change in the functionality of samples treated with CSE, CGA, genistein, and melatonin. The highest change in the antioxidant capacity of the proteins was observed in the genistein- and melatonin-containing samples. The CSE sample showed an antioxidant capacity significantly $(p<0.05)$ higher than that obtained for controls (BSA and MGO).
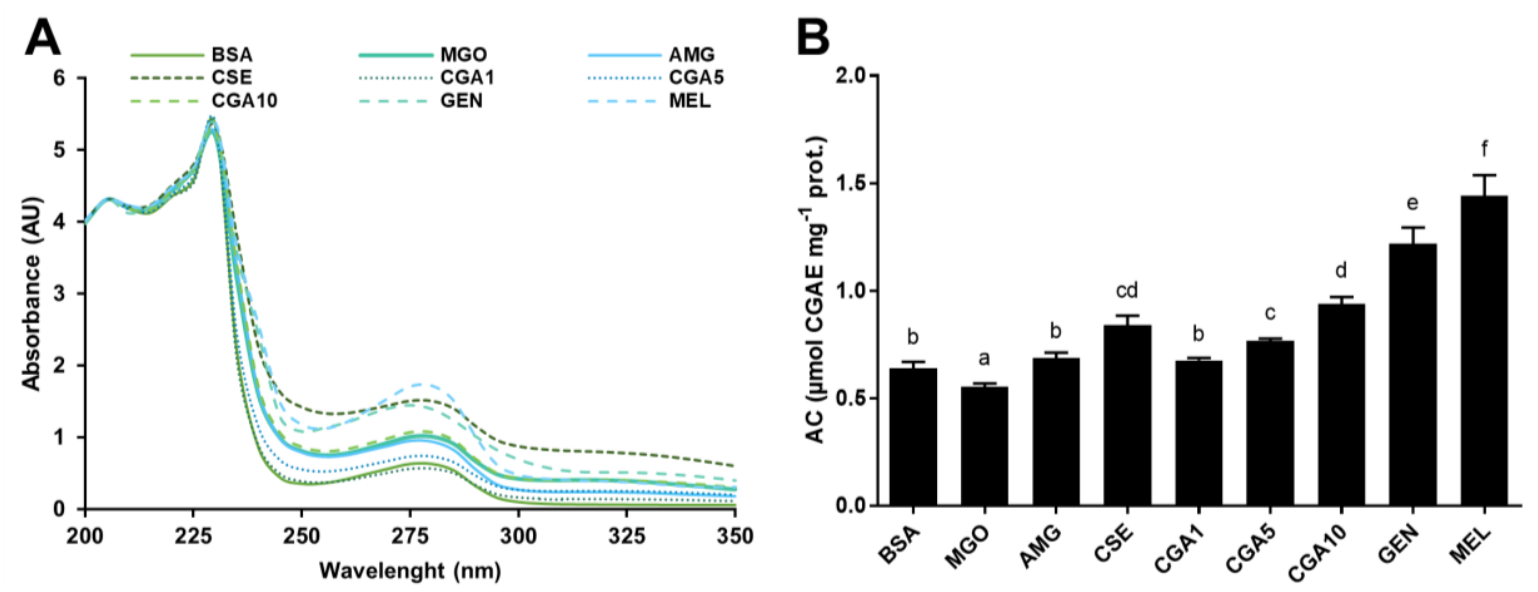

Figure 5. UV-Vis spectra (A) and antioxidant capacity (B) of the high molecular weight protein fractions (>30 kDa) isolated from the samples of the BSA-MGO glycation system $\left(72 \mathrm{~h}\right.$ agitation, $\left.37^{\circ} \mathrm{C}, \mathrm{pH} 7.4\right)$ BSA: negative control; MGO: BSA + methylglyoxal; AMG: BSA + methylglyoxal + aminoguanidine; CSE: BSA + methylglyoxal + CSE $\left(12,5 \mathrm{mg} \mathrm{mL}^{-1}\right)$; CGA1: BSA + methylglyoxal + $1 \mathrm{mmol} \mathrm{L}^{-1}$ CGA; CGA5: BSA + methylglyoxal + 5 mmol L${ }^{-1}$ CGA; CGA10: BSA + methylglyoxal $+10 \mathrm{mmol} \mathrm{L}^{-1}$ CGA; GEN: BSA + methylglyoxal $+5 \mathrm{mmol} \mathrm{L}^{-1}$ genistein; MEL: BSA + methylglyoxal $+5 \mathrm{mmol} \mathrm{L}^{-1}$ melatonin. Results are presented as mean $\pm \operatorname{SD}(n=3)$. Bars with different letters denote significant differences $(p<0.05)$ when subjected to Tukey multiple range test.

The PCA (Figure 6A) established four components, representing the first two $69.8 \%$ of the variability. The PC1 divided the samples into two groups, depending on the content of free amino groups (variable of higher weight for this component), with those on the righ of high content, and those on the left of low content. PC2, in turn, divided the samples treated with genistein from those treated with CGA. The study of similarities found among samples, according to their percentages of inhibition for the analysed parameters, is illustrated in Figure 6B. The dendrogram showed the grouping of the inhibitors in two clusters. In the first, samples were sub-clustered: GEN ( $5 \mathrm{mmol} \mathrm{L}^{-1}$ genistein), on the one hand, and MEL ( $5 \mathrm{mmol} \mathrm{L}^{-1}$ melatonin), AMG ( $5 \mathrm{mmol} \mathrm{L}-1$ aminoguanidine), CSE (12.5 mg mL${ }^{-1}$ ), and CGA1 (5 mmol L ${ }^{-1}$ CGA) on the other. In the second cluster, samples with CGA ( 5 and $10 \mathrm{mmol} \mathrm{L}^{-1}$ ) were found. Samples with CGA at concentrations of 5 and $10 \mathrm{mmol}$ $\mathrm{L}^{-1}$ (the highest concentrations) were separated by their inducing effect on the formation of protein carbonyls. The samples with genistein were separated, showing that this had compound the highest percentages of inhibition. CSE and AMG were grouped; their effects on the inhibition of glycoxidation reaction products formations were very similar. On the other hand, significant negative correlations $(p<0.01)$ were observed between the percentage of the inhibition of fluorescent AGE formation and the inhibition of amino group loss $(r=-0.778)$. 
A

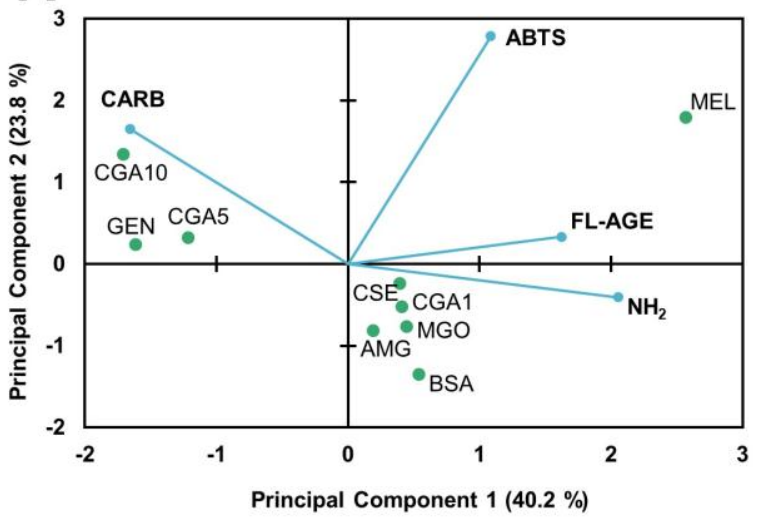

B

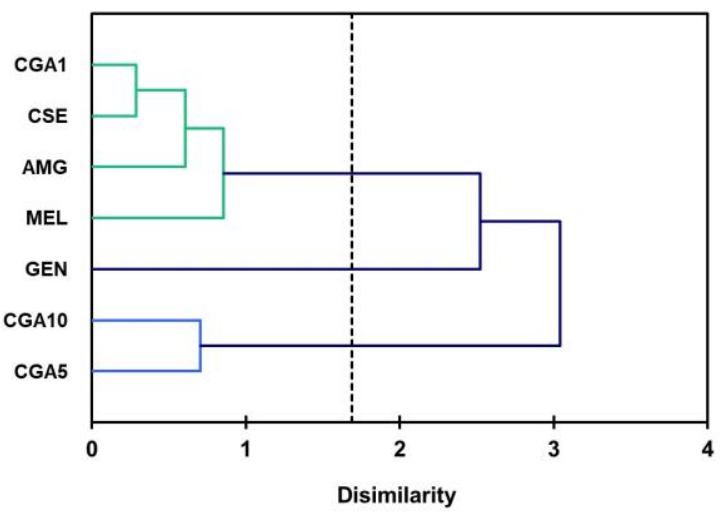

Figure 6. Biplot (scores of samples and load factors of each variable) of the principal component analysis (PCA) (A), including the content of free amino groups $\left(\mathrm{NH}_{2}\right)$, fructosamine (FRUCT), fluorescent AGE (FL-AGE), total AGE (T-AGE), and protein carbonyls (CARB) (A), and a dendrogram of the hierarchical cluster analysis of the glycation inhibitory activity (B) of the samples of the BSA-MGO glycation system (72 $\mathrm{h}$ incubation, $37^{\circ} \mathrm{C}$, $\mathrm{pH}$ 7.4) BSA: negative control; MGO: BSA + methylglyoxal; AMG: $\mathrm{BSA}+$ methylglyoxal + aminoguanidine; CSE: BSA + methylglyoxal + CSE $\left(12,5 \mathrm{mg} \mathrm{mL}^{-1}\right)$; CGA1: $\mathrm{BSA}+$ methylglyoxal $+1 \mathrm{mmol} \mathrm{L}^{-1}$ CGA; CGA5: BSA + methylglyoxal + $5 \mathrm{mmol} \mathrm{L}^{-1}$ CGA; CGA10: $\mathrm{BSA}+$ methylglyoxal + $10 \mathrm{mmol} \mathrm{L}^{-1}$ CGA; GEN: BSA + methylglyoxal $+5 \mathrm{mmol} \mathrm{L}^{-1}$ genistein; MEL: $\mathrm{BSA}+$ methylglyoxal $+5 \mathrm{mmol} \mathrm{L}^{-1}$ melatonin.

\subsection{Formation of Protein-Phytochemical Complexes}

To further confirm the formation of BSA-phytochemical complexes as the mechanism of action of CGA, genistein, and melatonin we evaluated the formation of complexes by fluorescence quenching and using molecular docking to investigate in silico how the phytochemicals bound to the protein.

\subsubsection{Fluorescence Spectra}

Fluorescence spectra for BSA-CGA, -GEN, and -MEL are depicted in Figure 7. Experiments carried out with glucose, MGO, and aminoguanidine demonstrated that these compounds did not complex with the protein (at the assayed concentrations) nor modify its fluorescence spectra. CGA and genistein highly quenched fluorescence, even at the lowest concentration tested $\left(5 \mu \mathrm{mol} \mathrm{L}{ }^{-1}\right)$.
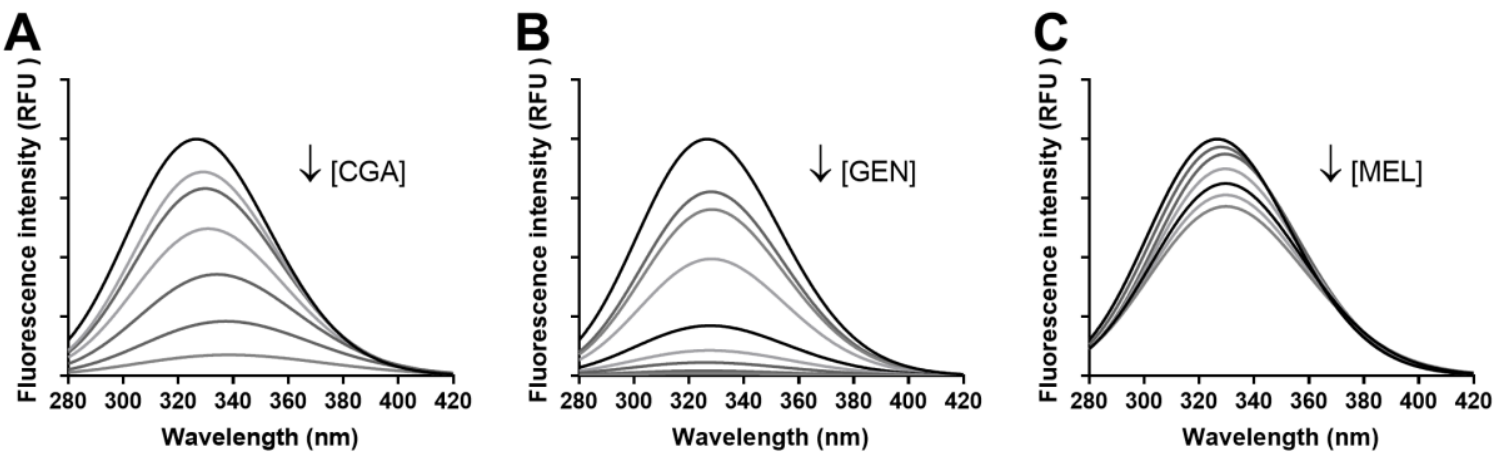

Figure 7. Fluorescence spectra of BSA showing fluorescence quenching in the absence and presence of varying concentrations of CGA $\left(5-200 \mu \mathrm{mol} \mathrm{L}^{-1}\right)(\mathbf{A})$, genistein $\left(5-1000 \mu \mathrm{mol} \mathrm{L}^{-1}\right)(\mathbf{B})$, and melatonin $\left(5-200 \mu \mathrm{mol} \mathrm{L}^{-1}\right)(\mathrm{C}) . \lambda_{\mathrm{ex}}=250 \mathrm{~nm}, \mathrm{pH} 7.4, \mathrm{~T}=310 \mathrm{~K}$.

The fluorescence intensity of BSA gradually diminished while increasing the concentration of the compound. Therefore, these results would confirm the formation of different strength protein-phytochemical complexes for the three bioactive compounds evaluated in this work. Since the 
compounds bound the protein differently, we calculated quenching and binding parameters of the phytochemicals (Table 2). For the fluorescence quenching measurement, the decrease in intensity is usually described by the well-known Stern-Volmer equation. In the linear range of the Stern-Volmer regression curve, the average $K_{S V}$ and $k_{q}$ were determined. Values of $k_{q}$ higher than the maximum value possible for diffusion-limited quenching in water $\left(\sim 1010 \mathrm{M}^{-1} \mathrm{~s}^{-1}\right)$ indicate an interaction among the compounds and BSA. Here, the $k_{q}$ values were in the range of $10^{12}$ to $10^{13}$, which confirmed the presence of a specific interaction occurring between CGA, genistein, and melatonin and BSA. Besides this, the binding constant value $\left(K_{a}\right)$ and the number of binding sites $(n)$ were obtained from the double-logarithm curve. The $K_{a}$ values suggest the tested phytochemical showed a moderate affinity to BSA since the documented $K_{a}$ values of non-covalent association of BSA with drugs are mostly in the range of $10^{4}-10^{6} \mathrm{M}^{-1}$.

Table 2. Experimentally determined quenching and binding parameters for BSA-phytochemical complexes obtained at equal conditions of $\mathrm{pH}(7.4)$ and temperature $\left(37^{\circ} \mathrm{C} / 310 \mathrm{~K}\right)$, including the Stern-Volmer quenching constant $\left(K_{S V}\right)$, bimolecular quenching constant $\left(k_{q}\right)$, binding constant $\left(K_{a}\right)$, and the number of binding sites $(n)$.

\begin{tabular}{ccccc}
\hline Compound & $\boldsymbol{K}_{\boldsymbol{S V}}\left(\mathbf{1 \mathbf { 1 0 } ^ { \mathbf { 4 } } \mathbf { ~ } \mathbf { ~ o l ~ L }} \mathbf{- 1}^{\mathbf{1}}\right)$ & $\boldsymbol{k}_{\boldsymbol{q}}\left(\mathbf{m o l ~ L}^{-\mathbf{1}} \mathbf{~ s}^{\mathbf{- 1}}\right)$ & $\boldsymbol{K}_{\boldsymbol{a}}\left(\mathbf{m o l ~ L}^{\mathbf{- 1}}\right)$ & $\boldsymbol{n}$ \\
\hline Chlorogenic acid & $4.42 \pm 0.14$ & $(7.64 \pm 0.24) \times 10^{12}$ & $4.78 \pm 0.19$ & $1.05 \pm 0.04$ \\
Genistein & $9.52 \pm 0.10$ & $(1.65 \pm 0.18) \times 10^{13}$ & $5.36 \pm 0.12$ & $1.12 \pm 0.03$ \\
Melatonin & $0.70 \pm 0.02$ & $(1.21 \pm 0.34) \times 10^{12}$ & $3.11 \pm 0.18$ & $0.82 \pm 0.04$ \\
\hline
\end{tabular}

\subsubsection{In Silico Prediction of Protein-Phytochemical Interactions}

Additionally, molecular docking studies illustrated the binding energies and the potential interaction of the compounds with the aminoacidic residues of BSA (Table 3, Figure 8). CGA, genistein, and melatonin exhibited strong binding energies (from -5.5 to $-9.0 \mathrm{kcal} \mathrm{mol}^{-1}$ ), demonstrating the occurrence of protein complex formation. As observed in the fluorescence spectra, the interaction of glucose, MGO, and aminoguanidine with BSA is weaker than that of CGA, genistein, and melatonin.

Table 3. Binding energies ( $\mathrm{kcal} \mathrm{mol}^{-1}$ ) between BSA (six different domains) and the pro-glycation (glucose and MGO) and antiglycative (aminoguanidine, CGA, genistein, and melatonin) agents predicted using in silico molecular docking and the interacting arginine and lysine residues.

\begin{tabular}{|c|c|c|c|c|c|c|c|}
\hline BSA Domain & GLU & MGO & AMG & CGA & GEN & MEL & Interacting Amino Acids * \\
\hline IA & -4.6 & -3.7 & -3.6 & -6.1 & -6.6 & -5.8 & Lys $^{4}, \operatorname{Arg}^{10}$, Lys $^{20}$, Lys $^{41}$, Lys $^{131}$, Lys $^{132}$ \\
\hline IB & -5.9 & -3.8 & -4.0 & -8.2 & -8.7 & -6.7 & 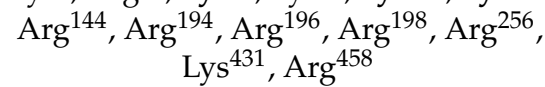 \\
\hline IIA & -5.9 & -3.8 & -4.1 & -9.0 & -8.4 & -6.8 & $\begin{array}{c}\mathrm{Arg}{ }^{194}, \underset{\mathrm{Lys}^{350}}{\operatorname{Arg}}{ }^{198}{ }^{\mathrm{Arg}}{ }^{347},{ }^{208}, \mathrm{Lrg}^{211} \mathrm{Arg}^{256}\end{array}$ \\
\hline IIB & -5.4 & -3.3 & -4.0 & -7.9 & -8.4 & -6.9 & 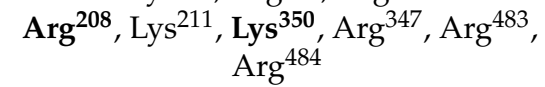 \\
\hline IIIA & -5.4 & -3.5 & -4.1 & -8.1 & -8.0 & -7.5 & 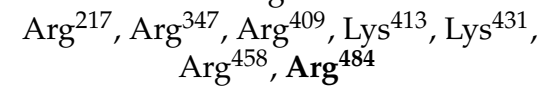 \\
\hline IIIB & -4.8 & -3.4 & -3.6 & -6.2 & -6.2 & -5.5 & $\begin{array}{c}\operatorname{Arg}^{427}, \operatorname{Arg}^{431}, \text { Lys }^{499}, \text { Lys }^{524}, \text { Lys }^{533} \\
\text { Lys }^{556}, \text { Lys }^{573}\end{array}$ \\
\hline
\end{tabular}

* Amino acids in bold interacted both with glucose and the studied compounds (CGA, genistein, or melatonin). 

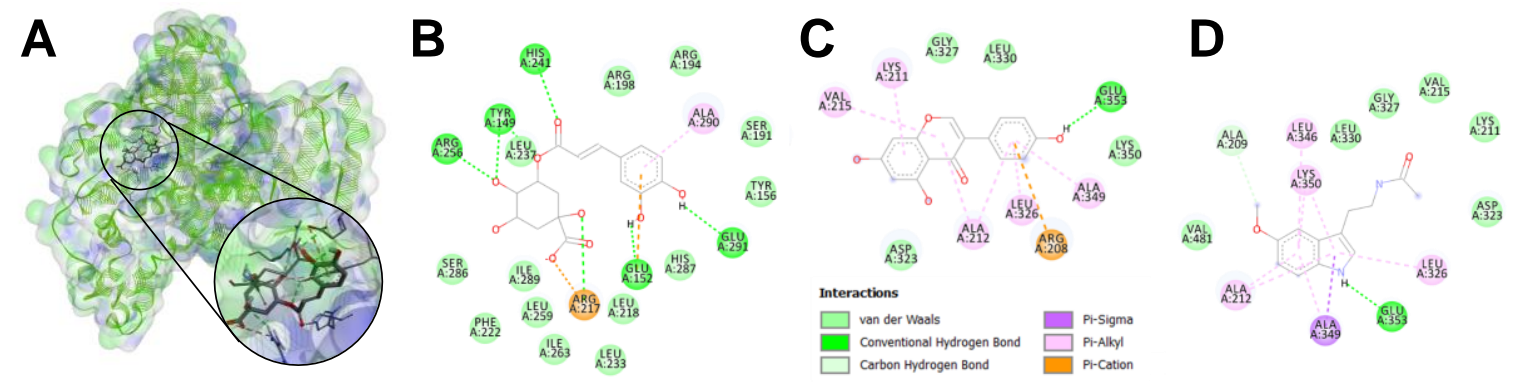

Figure 8. Representative molecular interaction of CGA with BSA (A), and 2D diagrams of the interaction of BSA with chlorogenic acid (B), genistein (C), and melatonin (D) determined using in silico molecular docking. The figure shows the compounds bound to the IIA domain of BSA and the interacting residues in each complex.

As observed, CGA, genistein, and melatonin could block a great number of lysine and arginine residues (BSA amino groups), the main reactants for the Maillard reaction. In most of the observed interactions, the phytochemicals would interact with the same residues that glucose would. Additionally, these three bioactive compounds might protect other lysine and arginine amino residues. Therefore, the formation of protein-phytochemical complexes was proven, both with fluorescence spectra and the molecular docking experiments.

\section{Discussion}

In the present work, the potential to inhibit the Maillard reaction of other CSE components besides CGA, such as isoflavones and melatonin, was evaluated for the first time. The results indicate that CSE is a sustainable source of phytochemicals, exhibiting higher TPC content than previously described [11]. The content of CGA and caffeine was higher in the present CSE than those values previously reported. The differences found in the concentrations of these bioactive compounds may be due to multiple factors, such as agronomic, geographical origin, species, variety, processing conditions (wet or dry), and roasting degree [29,30]. In the present research a mixture of Arabica and Robusta coffee silverskin (50:50 w/w), the most commercially available coffee species worldwide, was employed for obtaining CSE. This blend could better represent the coffee market and balance the differences in phytochemicals among the two varieties [31,32]. The melatonin content was higher than that present in the coffee drink $[33,34]$ and several orders of magnitude higher than in other foods considered rich in melatonin (nuts, cherries, or grapes, among others) [35]. The studied extract showed higher antioxidant capacity than other extracts from coffee by-products or extracts of coffee silverskin reported by others [14].

The reaction between the carbonyl group of a reducing sugar and a free amino group of a protein triggers a series of subsequent reactions, giving rise to fructosamine, carbonyls structures, and AGE. This study provides information about the influence of phytochemicals which compose CSE on the inhibition of different stages of Maillard reaction. The in vitro reaction models selected, BSA-GLU and BSA-MGO, generate Maillard reaction products of different nature. The BSA-GLU system showed the formation of early and advanced Maillard reaction products. In contrast, The BSA-MGO model provided useful information on the formation of AGEs and oxidation/glycoxidation products.

CSE and pure CGA, genistein, and melatonin inhibited the Maillard reaction under our particular experimental conditions. Pure phenolic compounds decreased the free amino groups' content, suggesting an inhibition of the Maillard reaction at its very early stages. Phenolic compounds can block amino groups when bound to the protein, inhibiting the formation of Amadori products and preventing glycation [36]. Genistein and melatonin were less effective inhibitors of the early stages of the Maillard reaction than CGA. However, they inhibited the formation of protein carbonyls through glycoxidation. CGA inhibited the formation of fructosamine, indicating that hydroxycinnamic acids have different antiglycative mechanisms than genistein and melatonin. The ability of CSE and its components to inhibit the formation of fluorescent and total AGE (glucose model system), at the 
tested concentrations, was higher than that of aminoguanidine. The antiglycative capacity of the extract seems not to be due solely to CGA, since, at similar concentrations of CGA, CSE has a higher inhibitory potential [14]. Other compounds present in CSE have been reported as potential inhibitors of the advanced glycation of proteins [14]. Among them, melanoidins have been suggested to inhibit AGE formation, acting as radical scavengers and inhibiting dicarbonyl reactive compound formation during glucose autoxidation $[37,38]$. Likewise, other antioxidant compounds, mainly phenolics and natural extracts, have also exhibited similar effects [39-41]. The measurement of AGE through ELISA techniques, however, entails some limitations (poor precision and susceptibility to matrix effects); the actual concept of AGE should be validated using HPLC-MS/MS techniques [42]. Carbonyl content measurement showed the protective effect of CSE, genistein, and melatonin against protein oxidation. Protein carbonylation is an index of the oxidation of amino groups in proteins, usually caused by oxidative stress or reaction with reducing sugars (glycation or glycoxidation). Previous studies have shown correlations among the levels of fluorescent AGE, $\mathrm{N}^{\varepsilon}$-(carboxymethyl)lysine (CML), and $\mathrm{N}^{\varepsilon}$-(carboxyethyl)lysine (CEL) with the levels of protein carbonyls $[43,44]$. CGA induced protein carbonyl formation. It is known that some CGA derivatives, such as oxidation products and isomers, may be able to act as substrates and precursors of the Maillard reaction and polymerisation reactions, which would explain the formation of carbonyls in the samples containing 5 and $10 \mathrm{mmol} \mathrm{L}^{-1}$ CGA (BSA-MGO system) [45]. In addition, CGA has been shown to exert pro-oxidant effects, apart from antioxidant effects. In oxidative conditions, such as the presence of MGO, a phenoxyl radical may be produced from CGA, reacting with proteins and oxidising them [46].

The direct protein-phytochemical interaction creates competition for free amino groups, an effect that decreases the binding of reactive carbonyls to protein, and therefore decreases AGE formation. At the same time, this loss of free amino groups is associated with a new functionality of protein, presenting a higher antioxidant capacity than the native one. Protein modifications indicated in this study may help to understand the mechanism of the action of antioxidants on protein glycation. The increased absorbance $(270-280 \mathrm{~nm})$ in the samples that were treated with genistein and melatonin, due to the formation of HMW protein-phytochemical complexes, correlated with the increased antioxidant capacity of the protein. Thus, the change in protein structure was associated with the change in protein function. Likewise, the fluorescence quenching and the in silico predicted interactions of CGA, genistein, and melatonin seemed to prove the formation of these protein-phytochemical complexes and exposed the strength and nature of the interactions. Previous studies using spectroscopic and docking techniques demonstrated that chlorogenic acid was able to interact with human serum albumin, and in a different manner depending on the isomer (chlorogenic acid, neochlorogenic acid, or cryptochlorogenic acid) [47]. Likewise, genistein interaction with BSA was assessed in another study, exhibiting similar quenching and binding parameters, that were improved when genistein was derivatised with peptides [48]. The protection of lysine and arginine amino residues from the reaction with the reactive carbonyl group of sugars or dicarbonyls was observed for both the phenolics (CGA and genistein), but also melatonin. Phenols bind to highly nucleophilic thiols, amino groups, and hydrophobic aromatic groups of proteins [49]. Three possible types of non-covalent interactions between proteins and phenolics have been proposed: hydrogen bonds, hydrophobic interactions, and ionic bonds [50]. Here, we observed them in silico, as well as carbon-hydrogen bonds, $\pi$-interactions, or salt bridges. Proteomic studies with Matrix-Assisted Laser Desorption/Ionization-Time Of Flight (MALDI-TOF) have determined which are the binding sites of CGA and its metabolites that, in turn, inhibit MGO binding [36]. CGA had higher reactivity than MGO, inhibiting the formation of most protein modification in both lysine and arginine residues [51].

The antiglycative ability of the studied compounds, however, was not due exclusively to their protein binding properties. The ability to inhibit AGE formation of these compounds may be associated with their antioxidant activity, their ability to chelate metal ions, to trap carbonyl radicals, or to inhibit protein-cross-linking activity [52-54]. Since most of the reactions comprised in the Maillard reaction (Figure 9A) include oxidation processes, the direct antioxidant effect of bioactive compounds may 
be one of the major ways of decreasing the production rate of Maillard reaction products and the formation of AGE.

A

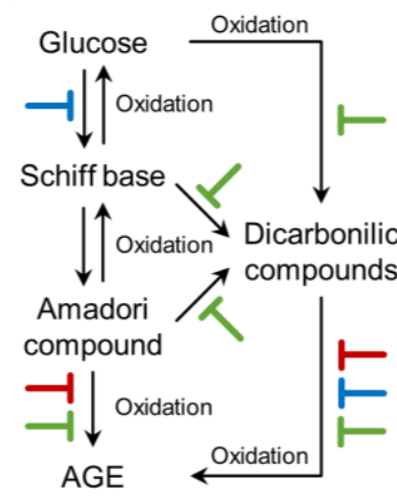

Mechanism of action
Protein-phytochemical interaction $\rightarrow$ CGA, GEN, MEL
B

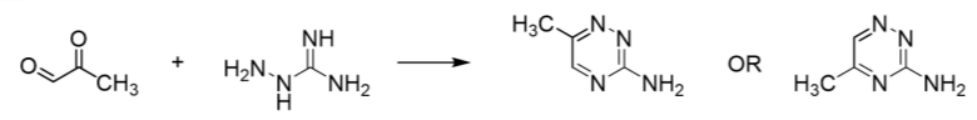

C<smiles>CC(=O)C=O</smiles>

D

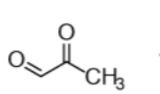

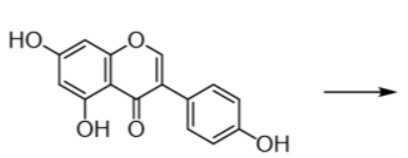

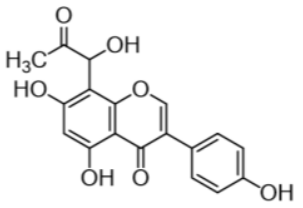

Figure 9. Illustrative diagram of the inhibitory mechanism (A) of coffee silverskin extract and the compounds (aminoguanidine, chlorogenic acid, genistein, and melatonin) studied in this work and the reactions of methylglyoxal trapping by aminoguanidine (B), chlorogenic acid (C), and genistein (D).

As shown, aminoguanidine does not interfere with the formation of early Maillard reaction products (Amadori compounds) but inhibits subsequent rearrangements which are essential for crosslinking reactions, working as a post-Amadori reactive carbonyls quencher (Figure 9B) $[55,56]$. We demonstrated that, conversely to the other studied compounds, aminoguanidine cannot bind the protein nor form BSA-aminoguanidine complexes.

The results suggest that the antiglycative capacity of CGA may be due to several mechanisms (Figure 9A,C), including its antioxidant character, inhibiting fructosamine degradation, as well as its binding to BSA, inhibiting the formation of fructosamine and AGE, and to its MGO trapping capacity (Figure 9C) [14]. CGA could inhibit the formation of fructosamine. CGA, at the concentrations found in CSE, may play a major role in inhibiting the Maillard reaction.

The results show that the binding capacity of genistein to proteins, with the consequent change in structure-function, decreases the formation of AGE. It was also reported that genistein inhibits the degradation of Amadori products, inhibiting the formation of carbonyls (and consequent protein oxidation) and the formation of AGE. Genistein would also have the ability to form adducts with MGO (Figure 9D) $[15,16]$. Genistein and other isoflavones that are in lower concentration than CGA may display a minor, but significant contribution to the total antiglycative capacity of CSE.

Melatonin, a compound with a non-phenolic structure, showed a primarily antioxidant behaviour, and it is also able to join to proteins, modifying their structure and functionality. The results seem to indicate the interaction protein melatonin is less favoured than that for other studied phytochemicals, and this may be due to other chemical reactions different to the Maillard reaction. Melatonin inhibited the formation of carbonyl compounds associated with protein oxidation and AGE formation.

CSE inhibited fructosamine and AGE formation, as well as protein oxidation. CSE antiglycative properties can be associated with the synergic effect of several phytochemicals, including CGA, isoflavones, and melatonin. CSE inhibited the Maillard reaction by all the mechanisms ascribed to the pure phytochemicals. In addition, melanoidins may also contribute to the observed effect [13]. Further studies for estimating the individual contribution of phytochemicals and compounds formed during roasting (melanoidins) to the antiglycative capacity of CSE should be conducted. 
However, the results derived from the present research seem to indicate that phytochemicals play a fundamental role as antiglycative agents of the extract.

The inhibitors of AGE production are considered targets in the management of diabetes and hyperglycaemia complications [57]. The search for natural alternatives to aminoguanidine and other antiglycative drugs with adverse side effects is of increasing interest. The use of natural extracts obtained from plants and food by-products can be a sustainable alternative to the use of synthetic drugs.

\section{Conclusions}

We described, for the first time, the potential role of other phytochemicals, besides CGA, that compose CSE, such as genistein and melatonin, as contributors of its antiglycative character. These bioactive compounds have demonstrated the ability to inhibit different steps of the Maillard reaction through different mechanisms. Future studies at other levels of experimentation should be conducted to demonstrate the potential of CSE to decrease the complications of diabetes and oxidative stress-related diseases by inhibiting different steps of the Maillard reaction.

Author Contributions: Conceptualization, M.R.-H. and M.D.d.C.; methodology, M.D.d.C. and M.H.; data curation, M.R.-H. and B.F.-G.; formal analysis, M.R.-H.; writing—original draft preparation, M.R.-H.; writing-review and editing, M.R.-H., B.F.-G., M.H., Y.A., M.A.M.-C., J.U., and M.D.d.C.; supervision, Y.A., M.A.M.-C., and M.D.d.C.; funding acquisition, M.A.M.-C. and M.D.d.C.

Funding: This research was funded by the SUSCOFFEE project (AGL2014-57239-R).

Acknowledgments: M.R.H thanks the JAE Intro fellowship (JAEINT_15_00086) and the FPU predoctoral program of the Ministry of Science, Innovation, and Universities (FPU15/04238).

Conflicts of Interest: The authors declare no conflict of interest.

\section{References}

1. Ames, J.M. Evidence against dietary advanced glycation endproducts being a risk to human health. Mol. Nutr. Food Res. 2007, 51, 1085-1090. [CrossRef] [PubMed]

2. Nowotny, K.; Jung, T.; Höhn, A.; Weber, D.; Grune, T. Advanced glycation end products and oxidative stress in type 2 diabetes mellitus. Biomolecules 2015, 5, 194-222. [CrossRef] [PubMed]

3. Uribarri, J.; del Castillo, M.D.; de la Maza, M.P.; Filip, R.; Gugliucci, A.; Luevano-Contreras, C.; Macias-Cervantes, M.H.; Markowicz Bastos, D.H.; Medrano, A.; Menini, T.; et al. Dietary Advanced Glycation End Products and Their Role in Health and Disease. Adv. Nutr. An Int. Rev. J. 2015, 6, 461-473. [CrossRef] [PubMed]

4. Kellow, N.J.; Coughlan, M.T. Effect of diet-derived advanced glycation end products on inflammation. Nutr. Rev. 2015, 73, 737-759. [CrossRef] [PubMed]

5. Martinez-Saez, N.; Fernandez-Gomez, B.; Cai, W.; Uribarri, J.; del Castillo, M.D. In vitro formation of Maillard reaction products during simulated digestion of meal-resembling systems. Food Res. Int. 2019, 118, 72-80. [CrossRef] [PubMed]

6. Davis, K.E.; Prasad, C.; Vijayagopal, P.; Juma, S.; Imrhan, V. Advanced Glycation End Products, Inflammation, and Chronic Metabolic Diseases: Links in a Chain? Crit. Rev. Food Sci. Nutr. 2016, 56, 989-998. [CrossRef] [PubMed]

7. Lund, M.N.; Ray, C.A. Control of Maillard Reactions in Foods: Strategies and Chemical Mechanisms. J. Agric. Food Chem. 2017, 65, 4537-4552. [CrossRef] [PubMed]

8. Yin, J.; Hedegaard, R.V.; Skibsted, L.H.; Andersen, M.L. Epicatechin and epigallocatechin gallate inhibit formation of intermediary radicals during heating of lysine and glucose. Food Chem. 2014, 146, 48-55. [CrossRef] [PubMed]

9. Li, Y.; Jongberg, S.; Andersen, M.L.; Davies, M.J.; Lund, M.N. Quinone-induced protein modifications: Kinetic preference for reaction of 1,2-benzoquinones with thiol groups in proteins. Free Radic. Biol. Med. 2016, 97, 148-157. [CrossRef] [PubMed]

10. Wu, C.-H.; Huang, S.-M.; Lin, J.-A.; Yen, G.-C. Inhibition of advanced glycation endproduct formation by foodstuffs. Food Funct. 2011, 2, 224. [CrossRef] [PubMed] 
11. Iriondo-DeHond, A.; Aparicio García, N.; Fernandez-Gomez, B.; Guisantes-Batan, E.; Velázquez Escobar, F.; Blanch, G.P.; San Andres, M.I.; Sanchez-Fortun, S.; del Castillo, M.D. Validation of coffee by-products as novel food ingredients. Innov. Food Sci. Emerg. Technol. 2019, 51, 194-204. [CrossRef]

12. Rebollo-Hernanz, M.; Zhang, Q.; Aguilera, Y.; Martin-Cabrejas, M.A.; Gonzalez de Mejia, E. Phenolic compounds from coffee by-products modulate adipogenesis-related inflammation, mitochondrial dysfunction, and insulin resistance in adipocytes, via insulin/PI3K/AKT signaling pathways. Food Chem. Toxicol. 2019, 132, 110672. [CrossRef] [PubMed]

13. Rebollo-Hernanz, M.; Zhang, Q.; Aguilera, Y.; Martin-Cabrejas, M.A.; Gonzalez de Mejia, E. Relationship of the Phytochemicals from Coffee and Cocoa By-Products with their Potential to Modulate Biomarkers of Metabolic Syndrome In Vitro. Antioxidants 2019, 8, 279. [CrossRef] [PubMed]

14. Mesías, M.; Navarro, M.; Martínez-Saez, N.; Ullate, M.; del Castillo, M.D.; Morales, F.J. Antiglycative and carbonyl trapping properties of the water soluble fraction of coffee silverskin. Food Res. Int. 2014, 62, 1120-1126. [CrossRef]

15. Wang, P.; Chen, H.; Sang, S. Trapping Methylglyoxal by Genistein and Its Metabolites in Mice. Chem. Res. Toxicol. 2016, 29, 406-414. [CrossRef] [PubMed]

16. Lv, L.; Shao, X.; Chen, H.; Ho, C.-T.; Sang, S. Genistein inhibits advanced glycation end product formation by trapping methylglyoxal. Chem. Res. Toxicol. 2011, 24, 579-586. [CrossRef] [PubMed]

17. Silvan, J.M.; Srey, C.; Ames, J.M.; Dolores del Castillo, M.; Silván, J.M.; Van de Lagemaat, J.; Olano, A.; del Castillo, M.D.; Van Nguyen, C.; Peng, X.F.; et al. Glycation is regulated by isoflavones. Food Funct. 2014, 5, 2036. [CrossRef] [PubMed]

18. Dontsov, A.E.; Vospelnikova, N.D.; Zack, P.P.; Ostrovsky, A.M.A. Antiglycation Activity of Melatonin. Dokl. Biochem. Biophys. 2017, 475, 283-286. [CrossRef]

19. Del Castillo, M.D.; Ibañez, E.; Amigo-Benavent, M.; Herrero, M.; Plaza del Moral, M.; Ullate, M. Application of Products of Coffee Silverskin in Anti-ageing Cosmetics and Functional Food. WO 2013/004873, 10 January 2013.

20. Singleton, V.L.; Orthofer, R.; Lamuela-Raventós, R.M. [14] Analysis of total phenols and other oxidation substrates and antioxidants by means of Folin-Ciocalteu reagent. Methods Enzymol. 1999, 299, 152-178.

21. Herrera, T.; Aguilera, Y.; Rebollo-Hernanz, M.; Bravo, E.; Benítez, V.; Martínez-Sáez, N.; Arribas, S.M.S.M.; del Castillo, M.D.M.D.; Martín-Cabrejas, M.A.M.A.M.A. Teas and herbal infusions as sources of melatonin and other bioactive non-nutrient components. LWT - Food Sci. Technol. 2018, 89, 65-73. [CrossRef]

22. Aguilera, Y.; Herrera, T.; Liébana, R.; Rebollo-Hernanz, M.; Sanchez-Puelles, C.; Martín-Cabrejas, M.A. Impact of Melatonin Enrichment during Germination of Legumes on Bioactive Compounds and Antioxidant Activity. J. Agric. Food Chem. 2015, 63, 7967-7974. [CrossRef] [PubMed]

23. Benitez, V.; Rebollo-Hernanz, M.; Hernanz, S.; Chantres, S.; Aguilera, Y.; Martin-Cabrejas, M.A. Coffee parchment as a new dietary fiber ingredient: Functional and physiological characterization. Food Res. Int. 2019, 122, 105-113. [CrossRef] [PubMed]

24. Martinez-Saez, N.; García, A.T.A.T.; Pérez, I.D.I.D.; Rebollo-Hernanz, M.; Mesías, M.; Morales, F.J.F.J.; Martín-Cabrejas, M.A.M.A.M.A.; del Castillo, M.D.M.D. Use of spent coffee grounds as food ingredient in bakery products. Food Chem. 2017, 216, 114-122. [CrossRef] [PubMed]

25. Fernandez-Gomez, B.; Ramos, S.; Goya, L.; Mesa, M.D.; del Castillo, M.D.; Martín, M.Á. Coffee silverskin extract improves glucose-stimulated insulin secretion and protects against streptozotocin-induced damage in pancreatic INS-1E beta cells. Food Res. Int. 2016, 89, 1015-1022. [CrossRef]

26. Morris, G.M.; Huey, R.; Lindstrom, W.; Sanner, M.F.; Belew, R.K.; Goodsell, D.S.; Olson, A.J. AutoDock4 and AutoDockTools4: Automated docking with selective receptor flexibility. J. Comput. Chem. 2009, 30, 2785-2791. [CrossRef]

27. Trott, O.; Olson, A.J. AutoDock Vina: improving the speed and accuracy of docking with a new scoring function, efficient optimization, and multithreading. J. Comput. Chem. 2010, 31, 455-461. [CrossRef] [PubMed]

28. Rebollo-Hernanz, M.; Zhang, Q.; Aguilera, Y.; Martin-Cabrejas, M.A.; Gonzalez de Mejia, E. Cocoa Shell Aqueous Phenolic Extract Preserves Mitochondrial Function and Insulin Sensitivity by Attenuating Inflammation Between Macrophages and Adipocytes in vitro. Mol. Nutr. Food Res. 2019, 63, 1801413. [CrossRef]

29. Alonso-Salces, R.M.; Serra, F.; Reniero, F.; HÉberger, K. Botanical and Geographical Characterization of Green Coffee (Coffea arabica and Coffea canephora): Chemometric Evaluation of Phenolic and Methylxanthine Contents. J. Agric. Food Chem. 2009, 57, 4224-4235. [CrossRef] 
30. Farah, A.; de Paulis, T.; Trugo, L.C.; Martin, P.R. Effect of roasting on the formation of chlorogenic acid lactones in coffee. J. Agric. Food Chem. 2005, 53, 1505-1513. [CrossRef]

31. Garrett, R.; Vaz, B.G.; Hovell, A.M.C.; Eberlin, M.N.; Rezende, C.M. Arabica and Robusta Coffees: Identification of Major Polar Compounds and Quantification of Blends by Direct-Infusion Electrospray Ionization-Mass Spectrometry. J. Agric. Food Chem. 2012, 60, 4253-4258. [CrossRef]

32. Bertone, E.; Venturello, A.; Giraudo, A.; Pellegrino, G.; Geobaldo, F. Simultaneous determination by NIR spectroscopy of the roasting degree and Arabica/Robusta ratio in roasted and ground coffee. Food Control 2016, 59, 683-689. [CrossRef]

33. Rebollo-Hernanz, M.; Fernández-Gómez, B.; Herrero, M.; Sanchez-Puelles, C.; Aguilera, Y.; del Castillo, M.D.; Martin-Cabrejas, M.A. Effect of brewing process on the content of bioactive compounds (caffeine, chlorogenic acids and melatonin) of coffee brews. In Proceedings of the EuroFoodChem XVIII, Madrid, Spain, 13-16 October 2015; p. 192.

34. Del Castillo, M.D.; Iriondo-DeHond, A.; Fernandez-Gomez, B.; Martinez-Saez, N.; Rebollo-Hernanz, M.; Martín-Cabrejas, M.A.; Farah, A. Coffee Antioxidants in Chronic Diseases. In Coffee: Consumption and Health Implications; Farah, A., Ed.; Royal Society of Chemistry: Cambridge, UK, 2019; pp. 20-56.

35. Martín-Cabrejas, M.A.; Aguilera, Y.; Benítez, V.; Reiter, R.J. Melatonin Synthesis in Fermented Foods. In Fermented Foods in Health and Disease Prevention; Academic Press, Elsevier: Cambridge, MA, USA, 2017; pp. 105-129. ISBN 9780128023099.

36. Fernandez-Gomez, B.; Ullate, M.; Picariello, G.; Ferranti, P.; Mesa, M.D.; del Castillo, M.D. New knowledge on the antiglycoxidative mechanism of chlorogenic acid. Food Funct. 2015, 6, 2081-2090. [CrossRef] [PubMed]

37. Echavarría, A.P.; Pagán, J.; Ibarz, A. Melanoidins Formed by Maillard Reaction in Food and Their Biological Activity. Food Eng. Rev. 2012, 4, 203-223. [CrossRef]

38. Morales, F.J.; Somoza, V.; Fogliano, V. Physiological relevance of dietary melanoidins. Amino Acids 2012, 42, 1097-1109. [CrossRef] [PubMed]

39. Sadowska-Bartosz, I.; Bartosz, G. Prevention of protein glycation by natural compounds. Molecules 2015, 20, 3309-3334. [CrossRef] [PubMed]

40. Silván, J.M.; Assar, S.H.; Srey, C.; Dolores del Castillo, M.; Ames, J.M. Control of the Maillard reaction by ferulic acid. Food Chem. 2011, 128, 208-213. [CrossRef] [PubMed]

41. Chinchansure, A.A.; Korwar, A.M.; Kulkarni, M.J.; Joshi, S.P. Recent development of plant products with anti- glycation activity: a review. RSC Adv. 2015, 5, 31113-31138. [CrossRef]

42. Gómez-Ojeda, A.; Jaramillo-Ortíz, S.; Wrobel, K.; Wrobel, K.; Barbosa-Sabanero, G.; Luevano-Contreras, C.; de la Maza, M.P.; Uribarri, J.; del Castillo, M.D.; Garay-Sevilla, M.E. Comparative evaluation of three different ELISA assays and HPLC-ESI-ITMS/MS for the analysis of Ne-carboxymethyl lysine in food samples. Food Chem. 2018, 243, 11-18. [CrossRef]

43. Adisakwattana, S.; Sompong, W.; Meeprom, A.; Ngamukote, S.; Yibchok-Anun, S. Cinnamic acid and its derivatives inhibit fructose-mediated protein glycation. Int. J. Mol. Sci. 2012, 13, 1778-1789. [CrossRef] [PubMed]

44. Shin, S.; Lee, J.-A.; Kim, M.; Kum, H.; Jung, E.; Park, D. Anti-Glycation Activities of Phenolic Constituents from Silybum marianum (Milk Thistle) Flower in Vitro and on Human Explants. Molecules 2015, 20, 3549-3564. [CrossRef]

45. Budryn, G.; Rachwal-Rosiak, D. Interactions of Hydroxycinnamic Acids with Proteins and Their Technological and Nutritional Implications. Food Rev. Int. 2013, 29, 217-230. [CrossRef]

46. Kalinowska, M.; Bajko, E.; Matejczyk, M.; Kaczyński, P.; Łozowicka, B.; Lewandowski, W. The Study of Anti-/Pro-Oxidant, Lipophilic, Microbial and Spectroscopic Properties of New Alkali Metal Salts of 5-O-Caffeoylquinic Acid. Int. J. Mol. Sci. 2018, 19, 463. [CrossRef] [PubMed]

47. Tang, B.; Huang, Y.; Ma, X.; Liao, X.; Wang, Q.; Xiong, X.; Li, H. Multispectroscopic and docking studies on the binding of chlorogenic acid isomers to human serum albumin: Effects of esteryl position on affinity. Food Chem. 2016, 212, 434-442. [CrossRef] [PubMed]

48. Long, X.; Zeng, Y.-F.; Liu, Y.; Liu, Y.; Li, T.; Liao, L.; Guo, Y. Synthesis of novel genistein amino acid derivatives and investigation on their interactions with bovine serum albumin by spectroscopy and molecular docking. RSC Adv. 2018, 8, 31201-31212. [CrossRef] 
49. Prigent, S.V.; Voragen, A.G.; Visser, A.J.; van Koningsveld, G.A.; Gruppen, H. Covalent interactions between proteins and oxidation products of caffeoylquinic acid (chlorogenic acid). J. Sci. Food Agric. 2007, 87, 2502-2510. [CrossRef]

50. Tang, D.; Li, H.-J.; Li, P.; Wen, X.-D.; Qian, Z.-M. Interaction of bioactive components caffeoylquinic Acid derivatives in Chinese medicines with bovine serum albumin. Chem. Pharm. Bull. (Tokyo) 2008, 56, 360-365. [CrossRef] [PubMed]

51. Fernandez-Gomez, B.; Nitride, C.; Ullate, M.; Mamone, G.; Ferranti, P.; del Castillo, M.D. Inhibitors of advanced glycation end products from coffee bean roasting by-product. Eur. Food Res. Technol. 2018, 244, 1101-1110. [CrossRef]

52. Murthy, P.S.; Naidu, M.M. Recovery of Phenolic Antioxidants and Functional Compounds from Coffee Industry By-Products. Food Bioprocess Technol. 2012, 5, 897-903. [CrossRef]

53. Gugliucci, A.; Bastos, D.H.M.; Schulze, J.; Souza, M.F.F. Caffeic and chlorogenic acids in Ilex paraguariensis extracts are the main inhibitors of AGE generation by methylglyoxal in model proteins. Fitoterapia 2009, 80, 339-344. [CrossRef]

54. Kim, J.; Jeong, I.-H.; Kim, C.-S.; Lee, Y.M.; Kim, J.M.; Kim, J.S. Chlorogenic acid inhibits the formation of advanced glycation end products and associated protein cross-linking. Arch. Pharm. Res. 2011, 34, 495-500. [CrossRef]

55. Edelstein, D.; Brownlee, M. Mechanistic studies of advanced glycosylation end product inhibition by aminoguanidine. Diabetes 1992, 41, 26-29. [CrossRef] [PubMed]

56. Nagai, R.; Murray, D.B.; Metz, T.O.; Baynes, J.W. Chelation: a fundamental mechanism of action of AGE inhibitors, AGE breakers, and other inhibitors of diabetes complications. Diabetes 2012, 61, 549-559. [CrossRef] [PubMed]

57. Fishman, S.L.; Sonmez, H.; Basman, C.; Singh, V.; Poretsky, L. The role of advanced glycation end-products in the development of coronary artery disease in patients with and without diabetes mellitus: A review. Mol. Med. 2018, 24, 59. [CrossRef] [PubMed]

(C) 2019 by the authors. Licensee MDPI, Basel, Switzerland. This article is an open access article distributed under the terms and conditions of the Creative Commons Attribution (CC BY) license (http://creativecommons.org/licenses/by/4.0/). 